1

4

5

6

7

8

9 5

\title{
Impacts, effectiveness and regional inequalities of the GeoMIP G1 to G4 solar radiation management scenarios
}

\author{
Xiaoyong $\mathrm{Yu}^{1,2}$, John C. Moore ${ }^{1}$, Xuefeng Cui ${ }^{{ }^{*}}$, Annette Rinke ${ }^{3}$, Duoying $\mathrm{Ji}^{1}$, Ben Kravitz ${ }^{4}$ \\ and Jin-Ho Yoon ${ }^{4}$ \\ ${ }^{1}$ State Key Laboratory of Earth Surface Processes and Resource Ecology, College of
}

Global Change and Earth System Science, Beijing Normal University, Beijing, 100875, China

${ }^{2}$ Department of Geography, Cambridge University, Cambridge, CB2 3EN, UK

${ }^{3}$ Alfred Wegener Institute Helmholtz Centre for Polar and Marine Research,

Telegrafenberg A43, 14473 Potsdam, Germany

${ }^{4}$ Atmospheric Sciences and Global Change Division, Pacific Northwest National

Laboratory, Richland, WA 99354, USA

(1)

17

(9)

(1)

2

6

*to whom correspondence should be addressed: College of Global Change and Earth System Science Beijing Normal University 19 Xinjiekou Wai street, Beijing, 100875, China. Email: xuefeng.cui@bnu.edu.cn. Phone: +86 13681113976

$$
-1 \text { - }
$$

(C) 2015. This manuscript version is made available under the Elsevier user license http://www.elsevier.com/open-access/userlicense/1.0/ 


\section{Abstract}

We evaluate the effectiveness and the regional inequalities of solar radiation management (SRM) in compensating for simultaneous changes in temperature and precipitation caused by increased greenhouse gas concentrations. We analyze the results from Earth System Models under four Geoengineering Model Intercomparison Project (GeoMIP) experiments with a modified form of the Residual Climate Response approach. Each experiment produces 50 model years of simulations: 13 models completed experiment $G 1$ (offsetting $4 \times \mathrm{CO}_{2}$ via solar reduction); 12 models completed experiment $G 2$ (offsetting $\mathrm{CO}_{2}$ that increased by $1 \%$ per year);, 3 models completed experiment $G 3$ (offsetting increasing radiative forcing under RCP4.5 with increasing stratospheric aerosol); and 7 models completed experiment $G 4$ (injection of $5 \mathrm{Tg} \mathrm{\textrm {SO } _ { 2 }} \mathrm{a}^{-1}$ into the stratosphere). The regional inequalities in temperature and precipitation compensation for experiments $G 1, G 3$ and $G 4$ are significantly different from their corresponding noise backgrounds for most models, but for $G 2$ they are not significantly different from noise. Differences in the regional inequalities and the actual effectiveness among the four SRM scenarios are not significant for many models. However, in more than half of the models, the effectiveness for temperature in the solar dimming geoengineering scenarios $(G 1$ and $G 2)$ is significantly higher than that in the $\mathrm{SO}_{2}$ geoengineering scenarios (G3 and $\left.G 4\right)$. The effectiveness of the four SRM experiments in compensating for temperature change is considerably higher than for precipitation. The methodology used highlights that large across-model variation in the treatment of key geoengineering processes (such as stratospheric 
57 aerosols) and the quantification of damage caused by climate change creates

58 significant uncertainties in any strategies to achieve optimal compensation

59 effectiveness across different regions.

\section{$60 \quad$ Keywords}

61 Solar Radiation Management; regional inequality; regional climate compensation

62 effectiveness; GeoMIP

\section{1. Introduction}

64 Frustrated by the slow progress in carbon dioxide emission reduction, increasing 65 numbers of scientists, politicians and members of the general public are devoting 66 attention to geoengineering, a set of technologies designed to counteract 67 anthropogenic climate change (e.g., Shepherd et al., 2009; Caldeira and Keith, 2010; 68 Crutzen, 2006; Wigley, 2006). Solar radiation management (SRM) is a category of 69 geoengineering that aims to block some solar radiation from reaching the Earth's 70 surface, e.g., by space mirrors in orbit (Mautner, 1989), stratospheric aerosol injection 71 (e.g., Budyko, 1977; Crutzen, 2006) or marine cloud seeding (e.g., Latham, 1990).

72 Many previous studies of SRM used single models (e.g., Bala et al., 2008; Fyfe et 73 al., 2013; MacCracken et al., 2012; Ricke et al., 2010). As such, determining the 74 modeled impacts and side effects of SRM on the Earth's climate system at global and 75 regional scales is confounded by questions of model dependence of the results. Rasch 76 et al. (2008) compared the results from two models that simulated stratospheric 77 sulfate aerosol injection, but the experiments performed with these models were not 
consistent, hence difficulties remained in interpreting aerosol effects. Jones et al.

79 (2010) compared the responses of two models to the continuous injection of $\mathrm{SO}_{2}$ into

80 the lower stratosphere at the rate of $5 \mathrm{Tg} \mathrm{a}^{-1}$, an experiment very similar to GeoMIP

81 experiment $G 4$ described below. Although there were some similarities in temperature

82 and precipitation response in these two models, their substantial differences prevented

83 the authors from making robust conclusions about the modeled effects of stratospheric

84 sulfate aerosol geoengineering.

85 To coordinate model simulations of SRM and determine the robust features of

86 climate models to reduced shortwave radiative forcing or sustained layers of

87 stratospheric aerosol, the Geoengineering Model Comparison Project (GeoMIP) was

88 established (Kravitz et al., 2011; see also Figure 1 for a graphical description of the

89 four core experiments). Several studies have investigated the climate responses to the

90 GeoMIP G1 (e.g., Kravitz et al., 2013a, 2013b; Schmidt et al., 2012; Tilmes et al.,

91 2013) and $G 2$ (Jones et al., 2013) experiments. These studies showed a regionally

92 diverse impact on temperature and precipitation, with considerable agreement

93 between models on broad features, such as a warming of the polar regions and cooling

94 of the tropics relative to pre-industrial norms. Kravitz et al. (2014) explored the

95 regional inequalities and effectiveness of global uniform SRM based on G1

96 multi-model results. GeoMIP studies of particular regions have thus far only focused

97 on the Arctic responses under G1 (Moore et al., 2014), G3 and G4 experiments

98 (Berdahl et al., 2014). 
In this paper, we (1) examine the robustness of modeled global and regional temperature and precipitation responses in the four core GeoMIP experiments and (2)

101 use the residual climate response (RCR) methodology (Moreno-Cruz et al., 2012;

102 discussed in Section 2.3 below) to evaluate climate change compensation 103 effectiveness and regional inequalities of temperature and precipitation in different

104 SRM experiments. The RCR methodology allows for a simple quantitative 105 comparison of different GeoMIP experiments, as it normalizes model results across 106 all of the various experiments and summarizes, as a resultant vector, the net climate

107 response of each climate variable irrespective of the numbers of models running each 108 experiment. This allows us to assess the effectiveness of different types of 109 geoengineering for compensating $\mathrm{CO}_{2}$ increases. The structure of this paper is as 110 follows: Section 2 describes the four GeoMIP experiments used in this study, as well 111 as the data processing methods; Section 3 discusses global and regional temperature 112 and precipitation changes, regional inequalities and the effectiveness of 113 geoengineering in compensating for changes from $\mathrm{CO}_{2}$ increases; finally, Section 4 114 provides a discussion of these results and their implications.

\section{2. Data and Analysis Methods}

\subsection{GeoMIP experiment and model description}

117 Among the four standard GeoMIP experiments, G1 and G2 are both designed to 118 simulate reduced shortwave radiative forcing by decreasing solar irradiance, while $G 3$ 119 and $G 4$ reduce net radiative forcing via the addition of sulfate aerosol precursors to 
121 that of pre-industrial levels with a simultaneous solar irradiance reduction. The global

122 mean top-of-atmosphere (TOA) radiation imbalance is specified to be within 0.1

$123 \mathrm{~W} / \mathrm{m}^{2}$ relative to the pre-industrial control simulation for the 50-year experiment

124 (Figure 1). Experiment $G 2$ is designed to balance a transient $\mathrm{CO}_{2}$ increase $(1 \%$ per

125 year increase in concentration) from pre-industrial levels by gradually decreasing

126 solar irradiance during the first 50 years of the experiment; after this period, SRM is

127 switched off while $\mathrm{CO}_{2}$ continues to increase at the rate of $1 \%$ per year for 20 years

128 (Figure 1). For comparison purposes, we also make use of three simulation results

129 from CMIP5 (Taylor et al., 2012) that serve as the background greenhouse gas

130 simulations for experiments $G 1$ and G2: piControl, which refers to the pre-industrial

131 control run; abrupt $4 x \mathrm{CO}$, which refers to the instantaneous quadrupling of $\mathrm{CO}_{2}$ from

132 pre-industrial levels; and 1 pctCO2, which refers to $1 \%$ per year $\mathrm{CO}_{2}$ increase from

133 pre-industrial levels.

134 Unlike $G 1$ and $G 2, G 3$ and $G 4$ are designed to reduce solar irradiance by

135 stratospheric $\mathrm{SO}_{2}$ injection (Figure 1). Over the 50 years of $G 3$, the injected $\mathrm{SO}_{2}$ mass

136 is gradually increased to counteract the gradually increased longwave radiative

137 forcing specified under the RCP4.5 scenario, thus maintaining top-of-atmosphere net

138 radiative flux at 2020 levels. In $G 4$, the annual amount of $\mathrm{SO}_{2}$ injected into the

139 stratosphere is a constant $5 \mathrm{Tg}$ per year for the first 50 years of $G 4$. G3 and G4 do not

140 specify how the models handle aerosols, and the models differ widely in their

141 representations of stratospheric chemistry, aerosol growth and dynamical transport 
142 schemes. Thus, it is expected that inter-model differences will be larger for $G 3$ and

$143 G 4$ than $G 1$ and $G 2$ (Kravitz et al., 2011). The CMIP5 experiment $r c p 45$, which is the

144 future climate state forced by RCP4.5 (Taylor et al., 2012), is used for comparison

145 purposes. The baseline climate for $G 1, G 2$ and the relevant greenhouse gas forcing

146 experiment is an average of the pre-industrial control simulation piControl over time.

147 The RCR vector-based methodology requires a prior state against which comparisons

148 can be made. In the $G 3$ and $G 4$ cases, this prior state cannot be simply the mean of

149 piControl because the RCP4.5 climate forcing continues from the historical forcing

150 record, which has been non-stationary. Therefore, we chose the average climate under

$151 r c p 45$ over the period 2010-2029 as the baseline for G3, G4, and $r c p 45$ (see Table 1).

152 During the first few years of all experiments, the short-term feedbacks and

153 transient climate responses will evolve as the models adjust to the new imposed

154 forcings. Therefore, all results reported here are averages over the years $11-50$ of the

155 simulations. We recognize that excluding only the first decade is insufficient to isolate

156 the transient response from the steady state response, especially in the abrupt $4 x \mathrm{CO} 2$

157 case, which imposes very large instantaneous changes in radiative forcing. This is a

158 compromise between including enough years of simulation to obtain useful statistics

159 regarding the climate response while excluding some of the more severe transient

160 changes in the climate. Excluding the first decade is consistent with several previous

161 GeoMIP studies (e.g., Schmidt et al., 2012; Kravitz et al., 2013a).

162 Table 1 lists the number of models available for each GeoMIP scenario and its

163 associated background simulation. The names and general description of the models 
164 are given in SI Table 1. In this study, with its emphasis on regional variations, we

165 focus on two important climate variables: near surface air temperature (SAT) and

166 precipitation, as in several previous studies (Kravitz et al., 2014; MacMartin et al.,

167 2013; Moreno-Cruz et al., 2012; Ricke et al., 2010; Ricke et al., 2013).

$168 \quad 2.2$ Regionalization

169 We followed Giorgi and Francisco (2000) in defining 22 regions to investigate

170 the patterns of temperature and precipitation change under SRM. These 22 regions

171 cover most of the global land area, and regional boundaries were chosen to represent

172 climatically and physiographically similar land areas. These regions are large enough

173 to produce climate predictions that are more statistically robust than those obtained

174 from grid cell level output (Giorgi and Francisco, 2000; Moreno-Cruz et al., 2012).

175 We calculated the area weighted temperature or precipitation change for each region

176 in each model. The 95\% significance level of temperature or precipitation change for

177 each region was also calculated with a two-tailed Student's $t$-test assuming each

178 model's data was independent.

$179 \quad 2.3$ Residual climate response method

180 To evaluate the potential regional inequalities resulting from SRM, as well as the

181 effectiveness of SRM, Moreno-Cruz et al. (2012) introduced the RCR methodology

182 with the objective of providing easily understood results suitable for policy- and

183 decision-makers. In the RCR approach, anthropogenic climate change and the climate

184 change compensated by SRM are represented by two vectors. Each component of 
185 these two vectors represents a given region's climate change under greenhouse gas

186 increases or SRM. The angle between these two vectors then represents the difference

187 between the SRM compensated climate and that under the $\mathrm{CO}_{2}$ equivalent $188 \quad\left(\mathrm{CO}_{2} \mathrm{e}\right)$-driven climate forcing alone.

189 The prerequisite of applying the RCR method is that regional responses are

190 approximately linear over the forcing range of interest (Moreno-Cruz et al., 2012).

191 Although the climate system is a non-linear system, and many climate responses are

192 nonlinear, several studies (Ban-Weiss and Caldeira, 2010; MacMartin et al., 2013;

193 Moreno-Cruz et al., 2012) have shown that modeled temperature and precipitation

194 responses over the radiative forcing ranges of their studies are approximately linear

195 with the amount of SRM.

196 The RCR approach is illustrated in Figure 2. The origin $\mathbf{O}$ represents the 197 reference state of a single climate variable Y (such as SAT or precipitation, but not a 198 combination of SAT and precipitation as in Moreno-Cruz et al., 2012 and Kravitz et 199 al., 2014; our approach avoids the problem of determining a relative importance 200 among different variables). The regional changes in Y from the reference state due to 201 elevated $\mathrm{CO}_{2} \mathrm{e}$ are represented as a $1 \times n$ dimension vector $\mathbf{Y}_{\mathrm{CO} 2 \mathrm{e}}$,

$$
\mathbf{Y}_{\mathrm{CO} 2 \mathrm{e}}=\left(y_{{\mathrm{CO} 2 e_{1}}_{1}}, y_{{\mathrm{CO} 2 e_{2}}_{2},,,} y_{{\mathrm{CO} 2 e_{i}}_{i},,,} y_{{\mathrm{CO} 2 e_{n}}_{n}}\right)
$$

203 where $n$ is the number of regions in the globe. Each component of $\mathbf{Y}_{\mathrm{CO} 2 \mathrm{e}}$ represents 204 the $\mathrm{CO}_{2} \mathrm{e}$ increasing induced $\mathrm{Y}$ change for a given region $i=1,2, \ldots n$. The residual 205 change in $\mathrm{Y}$ under SRM is represented by the vector $\mathbf{Y}_{\mathrm{RES}}$, 


$$
\mathbf{Y}_{\mathrm{RES}}=\left(y_{R E S_{1}}, y_{R E S_{2}},,, y_{R E S_{i}},,, y_{R E S_{n}}\right)
$$

In the vector $\mathbf{Y}_{\mathrm{CO} 2 \mathrm{e}}$ and $\mathbf{Y}_{\mathrm{RES}}$, the change in $\mathrm{Y}$ in each region is normalized by the corresponding inter-annual variability of $\mathrm{Y}$ under the baseline climate, as was done by

Ricke et al. (2010). The change compensated by SRM is represented by $\mathbf{Y}_{\text {SRM }}$ and is

$\mathbf{Y}_{\mathrm{CO} 2 \mathrm{e}}-\mathbf{Y}_{\mathrm{RES}}$. The angle $\varphi$ between $-\mathbf{Y}_{\mathrm{CO} 2 \mathrm{e}}$ and $\mathbf{Y}_{\mathrm{SRM}}$ represents the regional inequality in the effectiveness of compensating Y change by SRM and is calculated as follows:

For a non-zero $\mathbf{Y}_{\mathrm{SRM}}$, if $\varphi$ is $0^{\circ}$, all regions are equally compensated by SRM; if

$214 \varphi$ is $180^{\circ}$, SRM equally increases all regional changes from the elevated $\mathrm{CO}_{2} \mathrm{e}$ instead

215 of compensating for them. $\mathbf{Y}_{\text {RES_OPT }}$ is the minimum-norm residual change for a given

216 angle between $\mathbf{Y}_{\mathrm{CO} 2 \mathrm{e}}$ and $\mathbf{Y}_{\mathrm{SRM}}$. Geometrically, $\mathbf{Y}_{\mathrm{RES} \_\mathrm{OPT}}$ is perpendicular to $\mathbf{Y}_{\mathbf{S R M}}$ and

217 represents the minimum distance from the baseline to $\mathbf{Y}_{\mathbf{S R M}}$. $\mathbf{Y}_{\mathrm{RES} \_ \text {OPT }}$ is assumed to 218 be reached by adjusting the radiative forcing due to SRM equally in all regions. The 219 norm of $\mathbf{Y}_{\text {RES_OPT }}$ depends on $\varphi$ and the norm of $\mathbf{Y}_{\mathrm{CO} 2 \mathrm{e}}$. A larger $\varphi$ or norm of $\mathbf{Y}_{\mathrm{CO} 2 \mathrm{e}}$ means a larger norm of $\mathbf{Y}_{\text {RES_OPT. }}$ that regional damages $\mathrm{D}$ are a quadratic function of the regional change normalized

223 by the inter-annual variability of the baseline climate, so the damage caused by the 224 change in Y could be approximately expressed as follows:

$$
\begin{aligned}
& \mathrm{D}_{\mathrm{CO} 2 \mathrm{e}} \propto\left\|\mathbf{Y}_{\mathrm{CO} 2 \mathrm{e}}\right\|^{2} \\
& \mathrm{D}_{\mathrm{RES}} \propto\left\|\mathbf{Y}_{\mathrm{RES}}\right\|^{2} \\
& \mathrm{D}_{\text {RES_OPT }} \propto\left\|\mathbf{Y}_{\text {RES_OPT }}\right\|^{2}
\end{aligned}
$$


that other damage functional forms have been used in previous studies (e.g., Cline,

1992; Manne et al., 1995; Peck and Teisberg, 1992; Peck and Teisberg, 1994).

Moreover, there is no indication that a single damage functional form applies equally

to all regions or situations. The quadratic function used here is a simple option, but

we make no claim that it is more or less valid than other choices.

The percentage of damages compensated by SRM, as calculated from the regional change in the climate variable $\mathrm{Y}$, can be represented as:

$$
\left(1-\frac{\left\|\mathbf{Y}_{\text {RES }}\right\|^{2}}{\left\|\mathbf{Y}_{\text {CO } 2 \mathrm{e}}\right\|^{2}}\right) \times 100 \%
$$

We define the quantity in Equation 7 to be the actual effectiveness of particular SRM scenario. The optimal effectiveness of a particular SRM scenario for a given $\varphi$ is then:

$$
\left(1-\frac{\left\|\mathbf{Y}_{\text {RES _OPT }}\right\|^{2}}{\left\|\mathbf{Y}_{\text {CO 2e }}\right\|^{2}}\right) \times 100 \%=\left(1-\sin ^{2} \varphi\right) \times 100 \%
$$

An effectiveness of $100 \%$ means that the SRM perfectly compensated for all the change in climate variable $\mathrm{Y}$; if the effectiveness is negative, then the SRM increased the change in $\mathrm{Y}$, rather than compensating for it.

The adjustment percentage of the SRM-compensated change to obtain optimal compensation effectiveness in $\mathrm{Y}$ is calculated as:

$$
\left(\frac{\left\|\mathbf{Y}_{\mathrm{CO} 2 \mathrm{e}}\right\| \cdot \cos [(\varphi)}{\left\|\mathbf{Y}_{\mathrm{SRM}}\right\|}-1\right) \times 100 \%
$$

Moreno-Cruz et al. (2012) applied RCR to one geoengineering scenario and for only a single model, whereas here we use RCR to quantify temperature and precipitation compensation effectiveness and regional inequalities in multiple models for four SRM 
247 scenarios. Each model's compensation effectiveness and assessments of regional 248 inequalities are taken as independent measurements for the purpose of producing 249 multi-model ensemble means and standard deviations. To investigate the behaviors of $250 \varphi$, actual effectiveness, and optimal effectiveness due to natural variability, we 251 divided the piControl runs of each model into several parts, each part containing 40 252 continuous years of simulation. We then can define the first 40 years as the 253 'reference' case and the remainder as 'perfect geoengineering', in which the climate is 254 exactly returned to preindustrial conditions. The differences between the 'perfect 255 geoengineering' and 'reference' climates represent the noise caused by the model's 256 internal variability. We define the 'noise' values of the angle $\varphi$, actual effectiveness, 257 optimal effectiveness from use of the RCR method on these 'perfect geoengineering' 258 periods. Note the differences between 'perfect geoengineering' and 'reference' in 259 piControl may be not a good proxy of natural variability over 2010 to 2029 in $260 \mathrm{RCP} 4.5, G 3$ and $G 4$. We use it because there is no obvious way to find the "perfect 261 geoengineering' for the simulations from 2010 to 2029 in RCP4.5, and similarly for $262 \quad G 3$ and $G 4$.

263 The regional inequalities in Kravitz et al. (2014) were demonstrated by regional 264 differences in the path of temperature, precipitation and combined metric of 265 temperature and precipitation changes under different strength of solar irradiation 266 reduction. The Pareto improving, choosing the level of SRM that minimizes damages 267 for all regions without making any region worse off (Moreno-Cruze et al., 2012), for 268 temperature, precipitation and combined metric of temperature and precipitation also 
explored in Kravitz et al.(2014). We extend the work of Kravitz et al. (2014) by

270 quantifying the regional inequalities and effectiveness represented by these two

271 variables using the RCR method for each of the four GeoMIP experiments.

272 Furthermore, our method of assessing the level of natural variability allows us to test

273 the significance of regional inequalities and effectiveness in each experiment for each

274 model as well as the significance of differences among different experiments.

\section{Results}

\subsection{Global and regional SAT changes}

Figures 3 and 4 show the multi-model ensemble mean of the SAT change at the grid and regional scales under different experiments. For GISS-E2-R, the global mean temperature and precipitation under $G 3$ and $r c p 45$ are very similar to each other (SI

Figure 1). There is no sign of change in global climate after sulfate aerosol has been injected, possibly due to the efficacy of $\mathrm{SO}_{2}$ forcing in GISS-E2-R being relatively

282 small as compared to $\mathrm{CO}_{2}$ forcing. Therefore, the temperature and precipitation data 283 from this model are not included in the $G 3$ study.

284 The SAT under abrupt4xCO2 are obviously increased compared with piControl 285 (Figure 3a). The global average SAT increased $4.30 \pm 0.75^{\circ} \mathrm{C}$ (Table 2); these values 286 are similar to those in previous studies (Schmidt et al., 2012; Good et al., 2013;

287 Kravitz et al., 2013a). All the regional scale SATs (Figure 4a) show a statistically 288 significant increase (95\% significance level, see section 2.2 ; the same significance 289 level for regional change is used throughout this paper). G1 successfully addresses the 
substantial global mean warming under abrupt4xCO2, restoring the global average

291 SAT to its pre-industrial level (Table 2), but with relative warming over polar regions

292 and cooling over the tropics (Figure 3b). Previous studies (e.g., Govindasamy and

293 Caldeira, 2000; Kravitz et al., 2013a; Schmidt et al., 2012) attribute the main reason

294 for this SAT change pattern to the balancing of longwave greenhouse gas forcing by

295 seasonally and latitudinally varying shortwave forcing. The regional scale land

296 ensemble mean SAT change ranges from $-0.28^{\circ} \mathrm{C}$ to $0.96{ }^{\circ} \mathrm{C}$ (Figure $4 \mathrm{a}$ ).

297 SAT change under 1pctCO2 is much smaller but similar in spatial pattern to

298 abrupt4xCO2 (Figure 3c). G2 SAT change also have similar patterns to change under

299 Gl but with smaller magnitude and lower model agreement (Figure 3d). This is likely

300 due to the similar global radiative forcing spatial patterns between $G 1$ and $G 2$.

301 Regional scale land ensemble mean SAT change is between $0.00^{\circ} \mathrm{C}$ and $0.27^{\circ} \mathrm{C}$

302 (Figure 4b). The SATs are significantly increased over much of the northern mid- and

303 high-latitude land areas, but no regional scale SAT ensemble mean is larger than the

304 corresponding across-model variation (defined as the multi-model ensemble standard

305 deviation here and throughout this paper).

306 Over the period from 2030 to 2069, the global average SAT under rcp45

307 increased by $0.81 \pm 0.21^{\circ} \mathrm{C}$ compared with the baseline (average over $2010-2029$

308 under $r c p 45$; Table 2). Additionally, all regional land SATs are significantly increased 309 by $0.65{ }^{\circ} \mathrm{C}$ to $1.56^{\circ} \mathrm{C}$.

310 Under $G 3$, the global mean SAT moderately increases by $0.23 \pm 0.28{ }^{\circ} \mathrm{C}$ (Table 2 )

311 relative to the baseline. In contrast with $G 1$ and $G 2$, under which the SAT decreased 
312 generally over low latitude oceans, the SAT decrease areas under G3 are far fewer

313 and more dispersed, mainly over mid and high latitudes such as central Asia, north

314 Atlantic Ocean, northwest Australia, north Pacific Ocean and around Antarctica. At

315 regional scales, the ensemble mean land SAT changes range from $0.08{ }^{\circ} \mathrm{C}$ to $0.72{ }^{\circ} \mathrm{C}$.

316 However, none of the regional changes are significant because of the small number of

317 models in the $G 3$ ensemble and the large across-model variation.

318 For the geoengineering scenario $G 4$, the 40 year annual global mean SAT 319 increased by $0.28 \pm 0.31^{\circ} \mathrm{C}$ (Table 2). This is a slightly higher rise than under $G 3$. The 320 regional scale SAT increases range between $0.11{ }^{\circ} \mathrm{C}$ and $0.66{ }^{\circ} \mathrm{C}$. The SATs in 9 321 regions are significantly increased under G4. All the regional land SAT ensemble 322 means under $G 4$ increased relative to the baseline, and most regions have larger 323 increases than under G3. This illustrates that the greenhouse gas induced radiative 324 forcing in $r c p 45$ dominates that from $5 \mathrm{Tg} \mathrm{a}^{-1} \mathrm{SO}_{2}$ stratospheric injection over the 3252030 to 2069 period.

3263.2 Global and regional precipitation change

327 Figures 5 and 6 show precipitation changes at the grid scale and regional scale, 328 respectively. The global average precipitation increases by $0.15 \pm 0.06 \mathrm{~mm}$ day $^{-1}$ 329 under abrupt4xCO2 (Table 2 and Figure 5a). Precipitation is strongly and robustly (at 330 least ten of thirteen models agree on the sign of the change) increased over high 331 latitude regions and the equatorial ocean. Precipitation robustly decreases under the 332 sinking part of the Hadley Cell. These change patterns were also found by Schmidt et 333 al. (2012) and Kravitz et al. (2013a). 
335 (Table 2). The largest precipitation decrease occurs over equatorial parts of the Pacific

336 Ocean. The multi-model mean precipitation in 19 regions is decreased under G1;

337 changes in 16 of those regions are statistically significant (Figure 6a). The patterns

338 and global average of precipitation changes under $G 1$ are consistent with those

339 discussed by Schmidt et al. (2012) and Kravitz et al. (2013a). A reduction in solar

340 radiation imposed upon abrupt $4 \mathrm{XCO}_{2}$ causes an initial suppression in precipitation.

341 This suppression is sustained throughout experiment $G 1$ because of the lack of a slow

342 response, primarily because the strongest feedbacks are related to global mean

343 temperature changes, which are small (Kravitz et al., 2013b). From an energetic

344 perspective, the suppression in precipitation under $G 1$ is primarily a result of the

345 decrease of evaporative flux from the surface to the atmosphere (Kravitz et al., 2013b).

346 Evaporative flux decreases are in part caused by an increase in atmospheric stability

347 due to reduced insolation having a greater cooling effect on the surface than the

348 mid-troposphere (Bala et al., 2008; Kravitz et al., 2013a). Evaporation decreases are

349 also due to the $\mathrm{CO}_{2}$ physiological effect, whereby plants close their stomata under

350 high $\mathrm{CO}_{2}$ conditions, reducing evapotranspiration over land (Fyfe et al., 2013; Kravitz

351 et al., 2013b; Tilmes et al., 2013).

352 Precipitation changes under 1pctCO2 have weaker magnitudes than under

353 abrupt $4 x \mathrm{CO} 2$ while exhibiting similar spatial patterns. Under $G 2$, the precipitation

354 pattern is also similar to that under $G 1$, which may due to the similarity of the patterns

355 of radiative forcing, but with a smaller magnitude of change and lower model 
356 agreement. Only 5 of the 22 regions show statistically significant changes in 357 precipitation under $G 2$.

358 Globally averaged precipitation under rcp45 between 2030 and 2069 is

359 moderately increased by $0.04 \pm 0.02 \mathrm{~mm} \mathrm{day}^{-1}$ compared with the baseline. The 360 patterns of precipitation change under rcp45 are similar to those under abrupt $4 x C O 2$

361 and 1pctCO2. Regional-scale land precipitation changes range from -0.07 to $0.14 \mathrm{~mm}$

362 day $^{-1}$. The ensemble mean precipitation is increased in 18 regions, and in 9 of those

363 regions, the precipitation changes are statistically significant. The Amazon Basin has

364 the largest across-model precipitation change variation.

365 The ensemble mean of the global average precipitation change under $G 3$ is 366 negligible relative to the baseline, and the across-model variation $\left(0.02 \mathrm{~mm}\right.$ day $\left.^{-1}\right)$ is

367 much larger than the ensemble mean. No regional change in any land region is 368 significant.

369 Under $G 4$, the ensemble mean of the global average precipitation change is also 370 negligibly small with large across-model variation. The ranges of change of regional 371 scale precipitation under $G 4$ overlap closely with those under $r c p 45$. Precipitation is 372 significantly increased over East Asia and significantly decreased over the Amazon 373 Basin under $G 4$.

\subsection{Effectiveness and related regional inequalities of different SRM scenarios}

375 Figure 7 shows the regional inequality, and Figure 8 the actual effectiveness (line 376 and point) and corresponding noise (box) of individual models for scenarios $G 1$ to $G 4$ 377 for temperature and precipitation. G1 has low noise in regional inequality of 
378

379

380

381

383

384

temperature $\left(0.6^{\circ} \sim 1.1^{\circ}\right.$; Figure 7$)$, while the noise is larger for $G 3$ and $G 4\left(3.4^{\circ} \sim 8.6^{\circ}\right)$ and larger again for $G 2\left(3.5^{\circ} \sim 11.7^{\circ}\right)$. Note that similar regional inequalities between different models does not necessarily mean that the regional changes of these models are similar, as regional inequality depends on the temperature or precipitation changes in 22 regions under both the SRM scenario and the corresponding elevated $\mathrm{CO}_{2}$ scenario. Regional inequality noise in precipitation $\left(G 1: 4.0^{\circ} \sim 8.0^{\circ} . G 2: 21.8^{\circ} \sim 37.6^{\circ}\right.$, $G 3$ and $G 4: 13.2^{\circ} \sim 42.6^{\circ}$ ) is larger than for temperature. The regional inequality of temperature for all models under $G 1, G 3$, and $G 4$ are statistically significant (defined as being larger than their corresponding noise levels; we use this definition in the remainder of this paper). For $G 2,5$ of 11 models have a regional inequality of temperature that is significantly different from noise. The regional inequalities of precipitation for all $G 1$ and $G 3$ models, as well as 6 of $7 G 4$ models, are significantly different from their corresponding noise levels. For $G 2$, the regional inequality of precipitation is significantly different from noise in 6 of 11 models. $G 4$ has the largest regional inequality across-model variations (multimodel ensemble standard deviation) for both temperature and precipitation.

Although temperature and precipitation inequalities of $G 1$ are smaller than $G 2$ for most of models, none of them are significant as none of the regional inequality differences between $G 1$ and $G 2$ are larger than corresponding noise in $G 2$ (Figure 7). The temperature and precipitation regional inequality differences between $G 3$ and $G 4$ are not significant for 2 of 2 models that simulated both $G 3$ and G4. Most models under the solar dimming geoengineering scenarios $(G 1$ and $G 2)$ have temperature and 
precipitation regional inequalities smaller than under the $\mathrm{SO}_{2}$ geoengineering

401 scenarios (G3 and $G 4$ ), but no more than half of the models are significantly smaller.

402 Figure 8 shows that for actual effectiveness of temperature, $G 1$ also has the 403 smallest noise among the four experiments (0.01\% 0.08\%) and is the closest to $100 \%$ 404 effective $(98.7 \%$ 99.8\%). The noise in actual effectiveness of temperature is $4050.5 \% \sim 5.6 \%$ for $G 2$ and $0.5 \% \sim 3.0 \%$ for $G 3$ and $G 4$. Under $G 2,8$ of 12 models are 406 significantly different from the noise, and all models in $G 3$ and $G 4$ are significantly 407 different from the noise. For actual effectiveness of precipitation, the noise in $G 1$ 408 models is small (0.6\% 2.1\%). G2, G3 and $G 4$ have larger noise (G2: 19.7\% 57.6\%; $409 G 3$ and $G 4: 6.3 \sim 58.5 \%$ ). Actual effectiveness of precipitation for $G 1$ to $G 4$ are 410 significantly different from their corresponding noise for most models $(G 1: 12 / 12 ; G 2$ : $411 \quad 6 / 11 ; G 3: 3 / 3 ; G 4: 6 / 7)$.

412 For 8 of 11 models that simulated both $G 1$ and $G 2$, temperature actual 413 effectiveness of $G 1$ is significantly higher than G2 (Figure 8). However, only 3 of 11 414 models' precipitation actual effectiveness of $G 1$ are significantly higher than $G 2$. 415 Temperature actual effectiveness of $G 3$ are significantly higher than $G 4$ for 2 of 2 416 models while none of models' precipitation actual effectiveness of $G 3$ are 417 significantly higher than $G 4$. More than half of the models under the solar dimming 418 geoengineering scenarios $(G 1$ and $G 2)$ have temperature actual effectivenesses that 419 are significantly higher than under the $\mathrm{SO}_{2}$ geoengineering scenarios (G3 and $\left.G 4\right)$. 420 For precipitation actual effectiveness, $G 1$ is significantly higher than for $G 4$ and $G 2$ 421 and significantly higher than $G 3$ for more than half the models. 
actual effectiveness, with the differences between GISS-E2-R and the other models

424 dominating (see Figure 7 and 8).

425 The high compensation effectiveness, small regional inequality for SAT, and the 426 lower compensation effectiveness with larger regional inequality for precipitation

427 under $G 1$ are all consistent with the results of Moreno-Cruz et al. (2012), although

428 Moreno-Cruz et al. (2012) only used one model. Previous studies also showed the 429 difficulty of simultaneous perfect compensation of temperature and precipitation 430 change by uniform SRM (e.g., Bala et al., 2008; Kravitz et al., 2013a; Moreno-Cruz et 431 al., 2012; Ricke et al., 2010; Tilmes et al., 2013).

432 Optimal compensation effectiveness is higher than actual compensation 433 effectiveness in all the four GeoMIP experiments (SI Figure 2, Table 3). G4 has the 434 largest SAT and precipitation ensemble mean compensation effectiveness increase, 435 changing from $80 \%$ to $95 \%$ and from $46 \%$ to $59 \%$, respectively (Table 3). These 436 effectiveness differences show that none of the four geoengineering experiments are 437 at their highest potential to compensate for temperature and precipitation changes 438 under the corresponding greenhouse gas forcing experiments.

439 The adjustment percentage of SRM-compensated change needed to achieve 440 optimal compensation effectiveness (SI Figure 3, Table 3) under $G 1$ and $G 2$ indicates 441 that these two experiments should have weaker solar reduction to reach optimum 442 precipitation compensation effectiveness. This is because the hydrological cycle is 443 more sensitive to short wave surface warming than it is to greenhouse gas induced 
444 surface warming (e.g., Bala et al., 2008; Kleidon and Renner, 2013). Thus, although

445 the cooling induced by solar irradiance reduction under $G 1$ and $G 2$ successfully

446 counteracted the warming induced by $\mathrm{CO}_{2}$ elevation, the resulting weakening of the

447 hydrological cycle due to geoengineering is greater than the strengthening due to

448 elevated $\mathrm{CO}_{2}$. The adjustment percentage of SRM-compensated change under other

449 experiments is not significant for precipitation in $G 3$ and $G 4$ and not significant for

450 SAT in any experiment. The across-model variation of adjustment percentages to

451 achieve optimal compensation effectiveness for SAT and precipitation are larger than

452 across-model variations in the other three metrics (regional inequality, actual

453 compensation effectiveness and optimal compensation effectiveness) used in this

454 study. This is because across-model variations in the other three metrics contribute to

455 the across-model variation of the adjustment percentage. The adjustment percentage

456 across-model variation for SAT and precipitation under $G 3$ and $G 4$ is larger than

457 those under $G 1$ and $G 2$.

458 4. Discussion and Conclusions

459 In this study four GeoMIP experiments were analyzed using the results from up

460 to 13 earth system models. We first investigated the robustness of global and regional

461 SAT and precipitation change. We then explored the regional inequality, climate

462 compensation effectiveness and adjustment percentage of SRM-compensated change

463 needed to achieve optimal climate compensation effectiveness based on multi-model

464 results. 
As previous studies have shown (e.g., Kravitz et al., 2013a; Jones et al., 2013), under the idealized SRM experiments of $G 1$ and $G 2$, the global average SATs are successfully restored close to pre-industrial levels, although with a relative tropical decrease and polar increase pattern. Here we quantify that the corresponding effectiveness, as measured by the RCR method, is quite high. However, these two experiments resulted in reduced global precipitation, thus their corresponding precipitation effectiveness is much smaller than those for SAT.

472 Among the four SRM scenarios, the regional inequalities of temperature and 473 precipitation compensation for $G 1, G 3$ and $G 4$ are significantly different from their 474 corresponding noise levels for most of models. However, the regional inequalities of 475 temperature and precipitation compensation for $G 2$ are not significantly different from 476 the noise for most, and half of models respectively. This may be caused by the low 477 signal to noise ratio in $G 2$. The regional inequality and actual effectiveness 478 differences among the four SRM scenarios for many models are not significant 479 compared with the noise, especially for regional inequality. However, in more than 480 half the models, temperature actual effectiveness under the solar dimming 481 geoengineering scenarios $(G 1$ and $G 2)$ are significantly higher than under the $\mathrm{SO}_{2}$ 482 geoengineering scenarios (G3 and $G 4)$.

483 The difference between actual and optimal effectiveness supports earlier analysis 484 (MacMartin et al., 2013) that balancing the TOA radiation budget does not produce 485 equal regional responses. The optimum effectiveness can be reached by reducing or 486 increasing the SRM, but the result depends on the choice of regions, the weighting 
487 given to each region, and the metric used to aggregate all regions - this was also

488 deduced from the single-model experiments (Moreno-Cruz et al., 2012). Our

489 multi-model analysis brings extra information on the sensitivity of these results to

490 model physics. Cleary results differ depending on the model used, especially in the

491 case of highly complex simulations such as $\mathrm{SO}_{2}$ injections. This results in much

492 across-model noise, but a reasonably robust conclusion that aerosol injection is less

493 effective that solar dimming, and more likely to result in regional inequalities of

494 climate response. Here we have assumed only globally uniform forcing from SRM. If

495 non-uniform optimization is available, via spatial and temporal varying SRM, the

496 regional inequality will certainly be different. Residual temperature and precipitation

497 changes in the worst-off region (however that is defined), or the required solar

498 reduction for the same residual climate change, may be reduced (MacMartin et al.,

499 2013). The metrics we use here show, as expected, that precipitation is inherently

500 more variable across different regions than temperature. The large across-model

501 variation in the adjustment percentage of compensated SAT and precipitation change

502 by SRM to achieve optimal compensation effectiveness sheds light on the uncertainty

503 accumulation effect in optimizing compensation effectiveness of SRM.

504 While caution is needed to interpret the results based purely on the RCR

505 methodology in this study, the findings are in broad agreement with other studies

506 using different methods or considerably fewer models. The RCR methodology is a

507 useful tool that aids in the visualization and comparison of multiple model climate

508 fields across many regions in a simple set of metrics. The regions here are assumed 
510 population loadings as desired (e.g. Moreno-Cruz et al., 2012). Perhaps more

511 fundamentally, we used (as have others) a simple quadratic damage function for

512 climate change. In practice, such decisions are beyond the remit of the natural

513 sciences and ultimately are decided by societal values. However, the inputs to the

514 analysis come from earth system models and, therefore, are limited by the quality of

515 the climate system representation in those models. Although the four SRM

516 experiments in GeoMIP represent far from real-world implementations of the SRM,

517 the robust features and contrasting areas of doubt are becoming clearer. To move

518 towards potentially more useful regional or seasonal geoengineering modeling

519 requires advances, the identification of key region-specific damage functions, and

520 better treatment of geoengineering methods in the earth system models.

521

522

523

524

525

526

527

528

529

530

531

532

533

534

535

536

537

538

539

540

\section{Acknowledgements}

We thank Juan Moreno-Cruz, Hans-F Graf, and an anonymous reviewer for their comments. We thank all participants of the Geoengineering Model Intercomparison Project and their model development teams, CLIVAR/WCRP Working Group on Coupled Modeling for endorsing GeoMIP, and the scientists managing the Earth System Grid data nodes who have assisted with making GeoMIP output available. We acknowledge the World Climate Research Programme's Working Group on Coupled Modelling, which is responsible for CMIP, and we thank the climate modeling groups for producing and making available their model output. For CMIP the U.S. Department of Energy's Program for Climate Model Diagnosis and Intercomparison provides coordinating support and led development of software infrastructure in partnership with the Global Organization for Earth System Science Portals.DJ, XY, XC and JCM thank all members of the BNU-ESM model group and support from the Joint Center for Global Change Studies (JCGCS), as well as the Center of Information and Network Technology at Beijing Normal University for assistance in publishing the GeoMIP dataset. Ben Kravitz is supported by the Fund for Innovative Climate and Energy Research (FICER). The Pacific Northwest National Laboratory is operated for the U.S. Department of Energy by Battelle Memorial 
Institute under contract DE-AC05-76RL01830. Simulations performed by Ben Kravitz were supported by the NASA High-End Computing (HEC) Program through the NASA Center for Climate Simulation (NCCS) at Goddard Space Flight Center.

\section{References}

Bala, G., Duffy, P.B.,Taylor, K.E., 2008. Impact of geoengineering schemes on the global hydrological cycle. Proceedings of the National Academy of Sciences, 105 (22): 7664-7669.

Ban-Weiss, G.A. and Caldeira, K., 2010. Geoengineering as an optimization problem. Environmental Research Letters, 5(3).

Berdahl, M., Robock, A., Ji, D., Moore, J.C., Jones, A., Kravitz, B., Watanabe, S., 2014. Arctic Cryosphere Response in the Geoengineering Model Intercomparison Project (GeoMIP) G3 and G4 scenarios. Journal of Geophysical Research: Atmospheres, 119(3): 1308-1321.

Budyko, M.I., 1977. Climatic changes. American Geophysical Union, Washington D.C.

Caldeira, K. and Keith, D.W., 2010. The need for climate engineering research. Issues in Science and Technology, 27(1): 57-62.

Cline, W.R., 1992. The economics of global warming. Institute of International Economics, Washington, DC.

Crutzen, P.J., 2006. Albedo enhancement by stratospheric sulfur injections: A contribution to resolve a policy dilemma? Climatic Change, 77(3-4): 211-219.

Fyfe, J.C., Cole, J.N.S., Arora, V.K., Scinocca, J.F., 2013. Biogeochemical carbon coupling influences global precipitation in geoengineering experiments. Geophysical Research Letters, 40(3): 651-655.

Giorgi, F. and Francisco, R., 2000. Evaluating uncertainties in the prediction of regional climate change. Geophysical Research Letters, 27(9): 1295-1298.

Good, P., Gregory, J.M., Lowe, J.A., Andrews, T., 2013. Abrupt CO2 experiments as tools for predicting and understanding CMIP5 representative concentration pathway projections. Climate Dynamics, 40(3-4), 1041-1053.

Govindasamy, B. and Caldeira, K., 2000. Geoengineering Earth's radiation balance to mitigate CO2-induced climate change. Geophysical Research Letters, 27(14), 2141-2144.

Jones, A., Haywood, J., Boucher, O., Kravitz, B., Robock, A., 2010. Geoengineering by stratospheric $\mathrm{SO}_{2}$ injection: results from the Met Office $\operatorname{HadGEM(2)}$ climate model and comparison with the Goddard Institute for Space Studies ModelE. Atmospheric Chemistry and Physics, 10(13): 5999-6006.

Jones, A., Haywood, J.M., Alterskjaer, K., Boucher, O., Cole, J.N.S., Curry, C.L., Irvine, P.J., Ji, D., Kravitz, B., Kristjánsson, J.E., Moore, J.C., Niemeier, U., Robock, A., Schmidt, H., Singh, B., Tilmes, S., Watanabe, S., Yoon, J.-H., 2013. The impact of abrupt suspension of solar radiation management (termination effect) in experiment G2 of the Geoengineering Model 
Intercomparison Project (GeoMIP). Journal of Geophysical Research: Atmospheres, 118(17): 9743-9752.

Kleidon, A. and Renner, M., 2013. A simple explanation for the sensitivity of the hydrologic cycle to surface temperature and solar radiation and its implications for global climate change. Earth System Dynamics, 4(2): 455-465.

Kravitz, B., MacMartin, D.G., Robock, A., Rasch, P.J., Ricke, K.L., Cole, J.N.S., Curry, C.L., Irvine, P.J., Ji, D., Keith, D.W., Kristjánsson, J.E., Moore, J.C., Muri, H., Singh, B., Tilmes, S., Watanabe, S., Yang, S. and Yoon, J.-H., 2014. A multi-model assessment of regional climate disparities caused by solar geoengineering. Environmental Research Letters, 9(7): 074013.

Kravitz, B., Caldeira, K., Boucher, O., Robock, A., Rasch, P.J., Alterskjær, K., Karam, D.B., Cole, J.N.S., Curry, C.L., Haywood, J.M., Irvine, P.J., Ji, D., Jones, A., Kristjánsson, J.E., Lunt, D.J., Moore, J.C., Niemeier, U., Schmidt, H., Schulz, M., Singh, B., Tilmes, S., Watanabe, S., Yang, S., Yoon, J.-H., 2013a. Climate model response from the Geoengineering Model Intercomparison Project (GeoMIP). Journal of Geophysical Research: Atmospheres, 118(15): 8320-8332.

Kravitz, B., Rasch, P.J., Forster, P.M., Andrews, T., Cole, J.N.S., Irvine, P.J., Ji, D., Kristjánsson, J.E., Moore, J.C., Muri, H., Niemeier, U., Robock, A., Singh, B., Tilmes, S., Watanabe, S., Yoon, J.-H., 2013b. An energetic perspective on hydrological cycle changes in the Geoengineering Model Intercomparison Project. Journal of Geophysical Research: Atmospheres, 118(23): 13,087-13,102.

Kravitz, B., Robock, A., Boucher, O., Schmidt, H., Taylor, K.E., Stenchikov, G., Schulz, M., 2011. The Geoengineering Model Intercomparison Project (GeoMIP). Atmospheric Science Letters, 12(2): 162-167.

Latham, J., 1990. Control of global warming? Nature, 347(6291): 339-340.

MacCracken, M.C., Shin, H.J., Caldeira, K. and Ban-Weiss, G.A., 2012. Climate response to imposed solar radiation reductions in high latitudes. Earth System Dynamics Discussions, 3(2): 715-757.

MacMartin, D.G., Keith, D.W., Kravitz, B., Caldeira, K., 2013. Management of trade-offs in geoengineering through optimal choice of non-uniform radiative forcing. Nature Clim. Change, 3(4): 365-368.

Manne, A., Mendelsohn, R., Richels, R., 1995. MERGE: A model for evaluating regional and global effects of GHG reduction policies. Energy Policy, 23(1): 17-34.

Mautner, M., 1989. Deep-space solar screens against climatic warming: technical and research requirements. Space utilization and applications in the Pacific, Proceedings of the Third Pacific Basin International Symposium on Advances in Space Science, Technology and Applications. American Astronautical Society, Los Angeles, pp. 711.

Moore, J.C., Rinke, A., Yu, X., Ji, D., Cui, X., Li, Y., Alterskjær, K., Kristjánsson, J.E., Muri, H., Boucher, O., Huneeus, N., Kravitz, B., Robock, A., Niemeier, 
U., Schulz, M., Tilmes, S., Watanabe, S., Yang, S., 2014. Arctic sea ice and atmospheric circulation under the GeoMIP G1 scenario. Journal of Geophysical Research: Atmospheres, 119(2): 567-583.

Moreno-Cruz, J.B., Ricke, K., Keith, D., 2012. A simple model to account for regional inequalities in the effectiveness of solar radiation management. Climatic Change, 110(3-4): 649-668.

Peck, S.C. and Teisberg, T.J., 1992. CETA: a model for carbon emissions trajectory assessment. The Energy Journal, 13(1): 55-78.

Peck, S.C. and Teisberg, T.J., 1994. Optimal carbon emissions trajectories when damages depend on the rate or level of global warming. Climatic Change, 28(3): 289-314.

Rasch, P.J., Tilmes, S., Turco, R.P., Robock, A., Oman, L., Chen, C.C., Stenchikov, G.L., Garcia, R.R., 2008. An overview of geoengineering of climate using stratospheric sulphate aerosols. Philos Transact A Math Phys Eng Sci, 366(1882): 4007-37.

Ricke, K.L., Moreno-Cruz, J.B., Caldeira, K., 2013. Strategic incentives for climate geoengineering coalitions to exclude broad participation. Environmental Research Letters, 8(1): 014021.

Ricke, K.L., Morgan, G., Allen, M.R., 2010. Regional climate response to solar-radiation management. Nature Geoscience, 3(8): 537-541.

Schmidt, H., Alterskjær, K., Bou Karam, D., Boucher, O., Jones, A., Kristjánsson, J.E., Niemeier, U., Schulz, M., Aaheim, A., Benduhn, F., Lawrence, M., Timmreck, C., 2012. Solar irradiance reduction to counteract radiative forcing from a quadrupling of $\mathrm{CO} 2$ : climate responses simulated by four earth system models. Earth Syst. Dynam., 3(1): 63-78.

Shepherd, J., 2009. Geoengineering the climate: science, governance and uncertainty. Royal Society, London.

Taylor, K.E., Stouffer, R.J., Meehl, G.A., 2012. An Overview of CMIP5 and the Experiment Design. Bulletin of the American Meteorological Society, 93(4): 485-498.

Tilmes, S., Fasullo, J., Lamarque, J.-F., Marsh, D.R., Mills, M., Alterskjær, K., Muri, H., Kristjánsson, J.E., Boucher, O., Schulz, M., Cole, J.N.S., Curry, C.L., Jones, A., Haywood, J., Irvine, P.J., Ji, D., Moore, J.C., Karam, D.B., Kravitz, B., Rasch, P.J., Singh, B., Yoon, J.-H., Niemeier, U., Schmidt, H., Robock, A., Yang, S., Watanabe, S., 2013. The hydrological impact of geoengineering in the Geoengineering Model Intercomparison Project (GeoMIP). Journal of Geophysical Research: Atmospheres, 118(19): 11,036-11,058.

Wigley, T.M.L., 2006. A combined mitigation/geoengineering approach to climate stabilization. Science, 314(5798): 452-454. 
673

674

675

676

677

678

679

680

681

682

683

684

685

686

687

688

689 
Figure 1 GeoMIP $G 1$ to $G 4$ schemes (reprinted from Kravitz et al., 2011). G1 is started from a control run. The instantaneous quadrupling of $\mathrm{CO}_{2}$ concentration from pre-industrial levels is balanced by a reduction in the solar constant until year 50. G2 also started from a control run. The positive radiative forcing of an increase in $\mathrm{CO}_{2}$ concentration of $1 \%$ per year is balanced by a decrease in the solar constant until year 50. G3 approximately balances the positive radiative forcing from the RCP4.5 scenario by an injection of $\mathrm{SO}_{2}$ or sulfate aerosols into the tropical lower stratosphere from year 2020 to year 2069. G4 experiment is based on the RCP4.5 scenario, where immediate negative radiative forcing is produced by an injection of $\mathrm{SO}_{2}$ into the tropical lower stratosphere at a rate of $5 \mathrm{Tg} \mathrm{yr}^{-1}$ from year 2020 to year 2069 .

Figure 2 RCR model illustration. $\mathbf{O}$ represents the baseline of climate variable $\mathrm{Y}$. $\mathbf{Y}_{\text {Co2e }}$ represents the regional changes of climate variable $\mathrm{Y}$ from the baseline $\mathbf{O}$ with elevated $\mathrm{CO}_{2} \mathrm{e} . \mathbf{Y}_{\mathrm{RES}}$ represents the residual change in variable $\mathrm{Y}$ under SRM. Angle $\varphi$ represents the regional inequality in the effectiveness of compensating $\mathrm{Y}$ change by

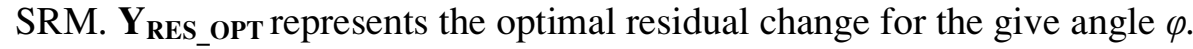

Figure 3 Ensemble mean of SAT anomalies for G1 - piControl, abrupt4xCO2piControl, G2 - piControl, lpctCO2 - piControl, G3 - rcp45_2010_2029, G4 rcp45_2010_2029, rcp45_2030_2069 - rcp45_2010_2029. For G1 - piControl, abrupt4xCO2 - piControl, stippling indicate where fewer than 10/13 models agreed on the sign of change; fewer than 9/12 models agreed for G2 - piControl and 1pctCO2 - piControl; fewer than 6/8 models agreed for rcp45_2030_2069 rcp45_2010_2029; fewer than 2/3 models agreed for G3 - rcp45_2010_2029; fewer than 5/7 models agreed for $G 4$ - rcp45_2010_2029.

720

Figure 4 Ensemble mean and standard deviation of area-weighted near surface air temperature for 22 regional anomalies in $\mathrm{Gl}$ - piControl, abrupt4xCO2 - piControl, G2 - piControl, 1pctCO2 - piControl, G3 - rcp45_2010_2029, rcp45_2030_2069 $r c p 45$ 2010_2029, G4 - rcp45_2010_2029. Diamonds indicate the regional anomalies passed a Student's $t$ test at the significance level of 0.05 .

Figure 5 As for Figure 3 but for precipitation anomalies.

732

Figure 6 As for Figure 4 but for precipitation regional anomalies.

Figure 7 Individual model, multi-model ensemble mean and standard deviation of regional inequality $\varphi\left({ }^{\circ}\right.$; equation 3 ) of experiment $G 1, G 2, G 3$ and $G 4$ for near surface air temperature and precipitation. Calculated noise levels for G3 and G4 are 
734 the same for same model as both experiments used $r c p 45$ as the elevated $\mathrm{CO}_{2} \mathrm{e}$

735 scenario. CESM-CAM5.1-FV was not included in the noise calculation for $G 1$ and

$736 \quad G 2$ as its piControl simulation only includes model 50 years.

737

738

Figure 8 As for Figure 7 but for actual compensation effectiveness (\%; equation 7).

739

740

741

742

743 
Table 1 Experiments used in this study.

748

\begin{tabular}{|c|c|c|c|c|}
\hline \multicolumn{2}{|c|}{ experiment } & \multirow{2}{*}{ Averaging period } & \multirow{2}{*}{ Baseline climate } & \multirow{2}{*}{$\begin{array}{c}\text { Number of } \\
\text { Models }\end{array}$} \\
\hline SRM & No SRM & & & \\
\hline$G 1^{\text {\& }}$ & abrupt $4 x \mathrm{CO} 2$ & experiment year $11-50$ & pre-industrial average & 13 \\
\hline$G 2^{\text {\& }}$ & $1 p c t C O 2$ & experiment year 11-50 & pre-industrial average & 12 \\
\hline$G 3^{+}$ & rcp45 & year 2030-2069 & $\begin{array}{c}\text { average over } \\
2010-2029 \text { under } r c p 45\end{array}$ & 3 \\
\hline G4 & rcp 45 & year 2030-2069 & $\begin{array}{c}\text { average over } \\
\text { 2010-2029 under } r c p 45\end{array}$ & 7 \\
\hline
\end{tabular}

${ }^{\&}$ CESM-CAM5.1-FV was not included in the noise calculation for $G 1$ and $G 2$ as its piControl simulation only includes model 50 years. As a result, the noise calculation involved 12 models in G1 and 11 models in G2.

+ 4 models in total have completed G3, but we exclude GISS-E2-R from the G3 analysis - see text.

752

Table 2 Ensemble mean and standard deviation of global average of SAT and precipitation change for G1 - piControl,

\begin{tabular}{lcc}
\hline experiment & $\Delta \mathbf{T}\left({ }^{\circ} \mathbf{C}\right)$ & $\Delta \mathbf{P}\left(\mathbf{m m} \mathbf{d a y}^{-\mathbf{1}}\right)$ \\
\hline G1 - piControl & $0.05 \pm 0.25$ & $-0.128 \pm 0.043$ \\
abrupt4xCO2 - piControl & $4.30 \pm 0.75$ & $0.152 \pm 0.055$ \\
G2 - piControl & $0.07 \pm 0.20$ & $-0.020 \pm 0.010$ \\
1pctCO2 - piControl & $0.71 \pm 0.15$ & $0.023 \pm 0.006$ \\
G3 - rcp45_2010_2029 & $0.23 \pm 0.28$ & $0.000 \pm 0.019$ \\
G4 - rcp45_2010_2029 & $0.28 \pm 0.31$ & $0.001 \pm 0.025$ \\
rcp45_2030_2069-rcp45_2010_2029 & $0.81 \pm 0.21$ & $0.043 \pm 0.018$ \\
\hline
\end{tabular}




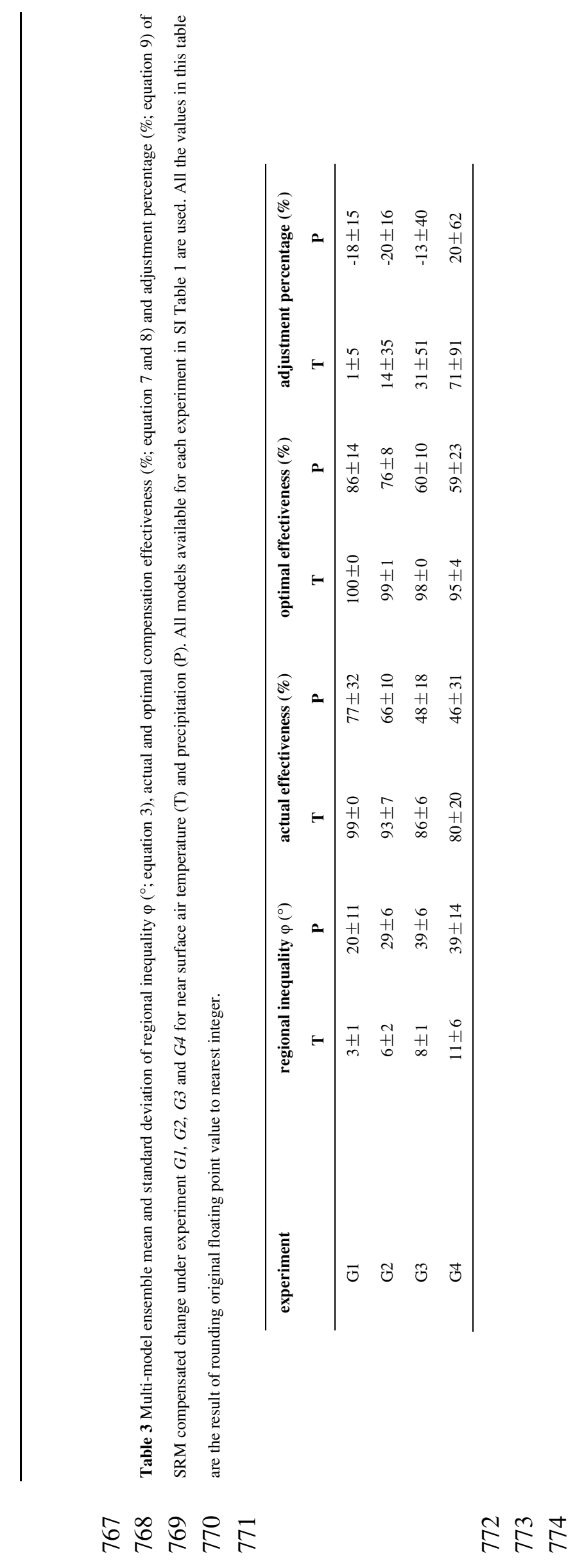



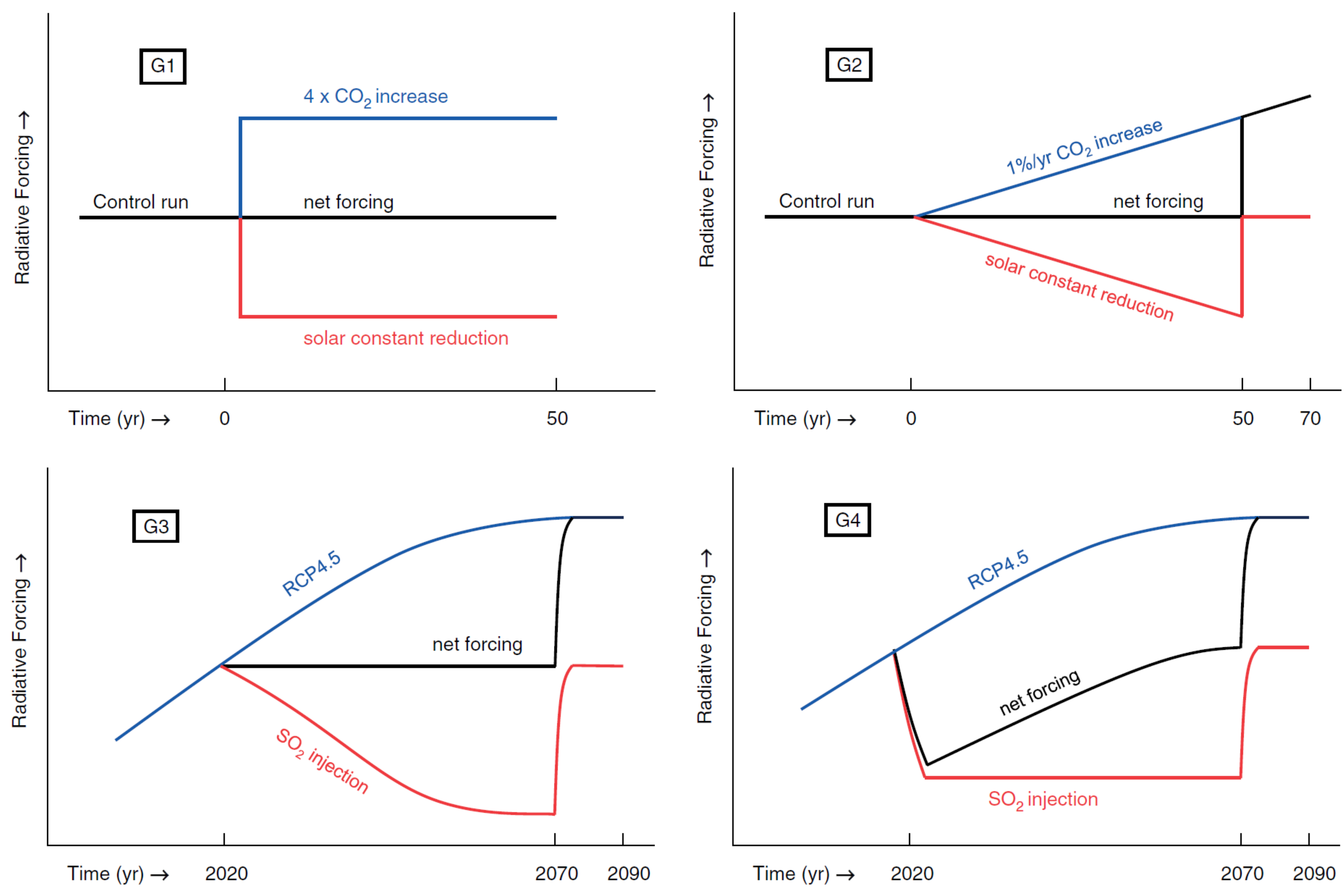


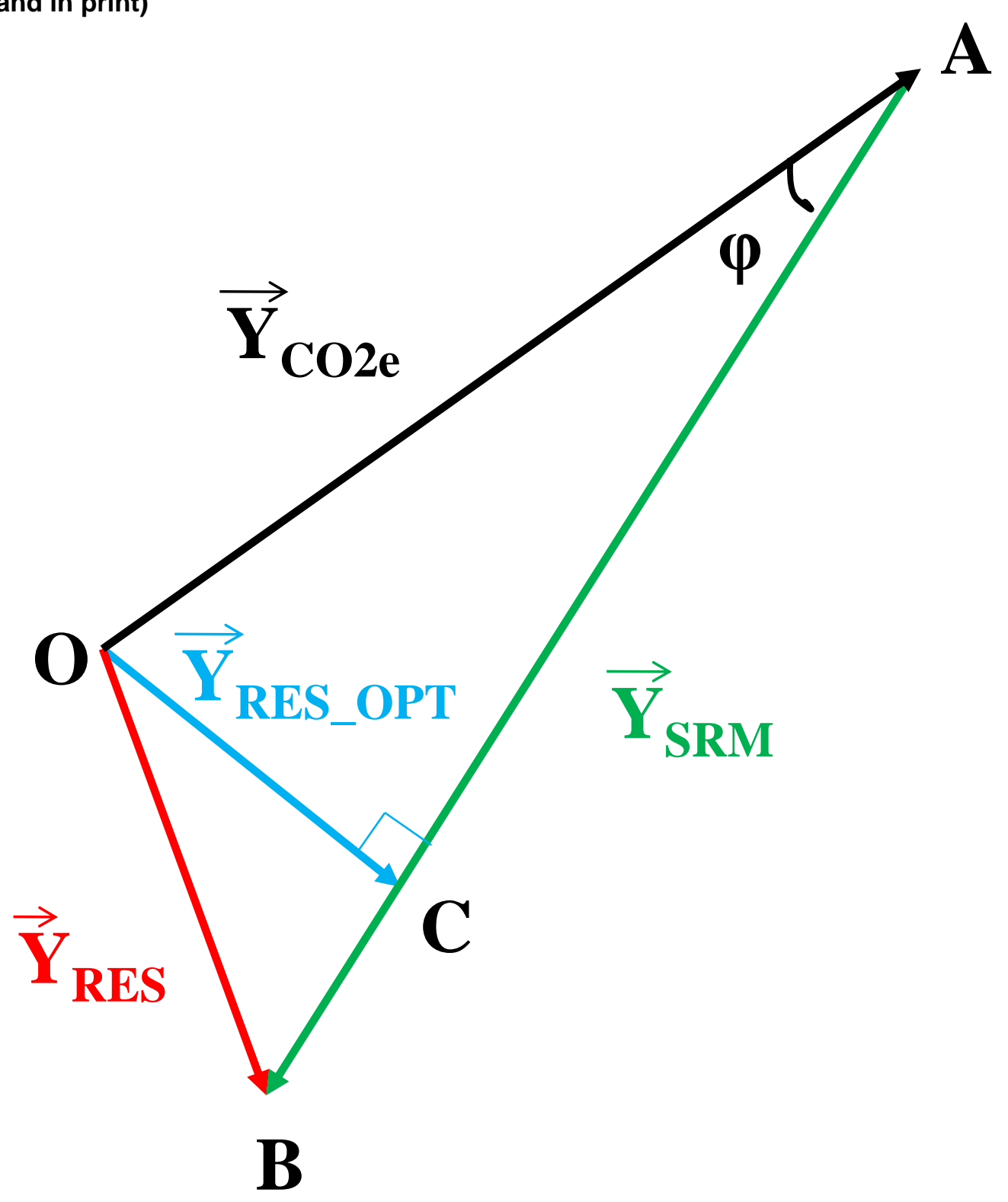


(a)

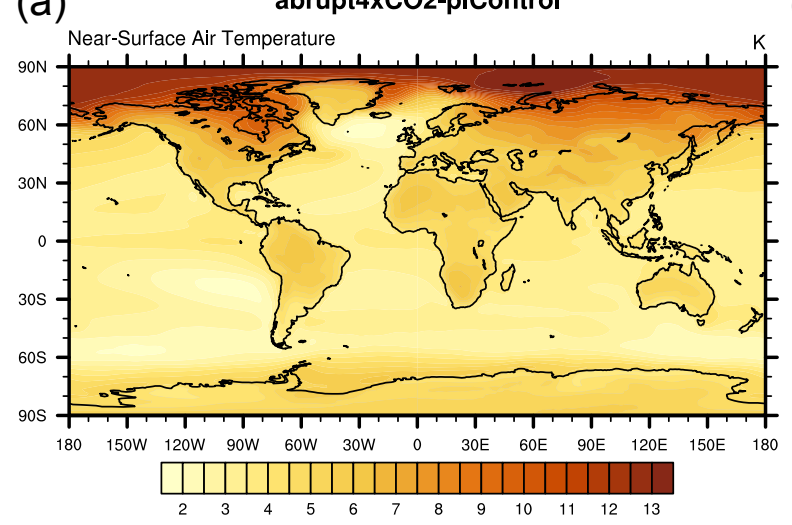

(c)

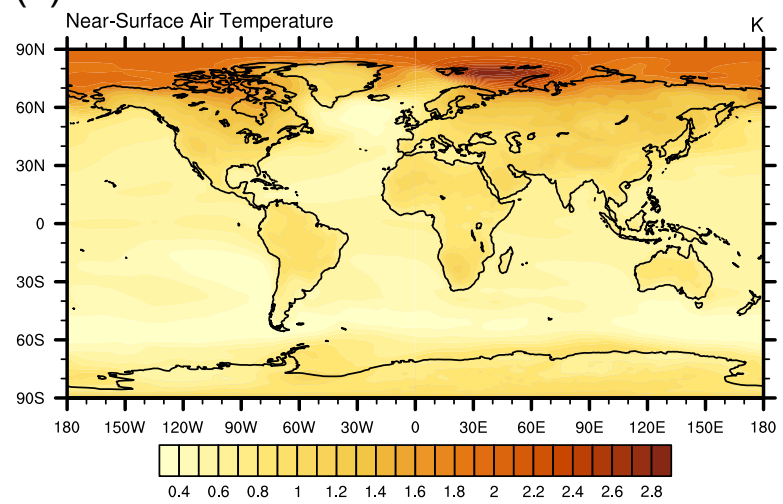

(e)

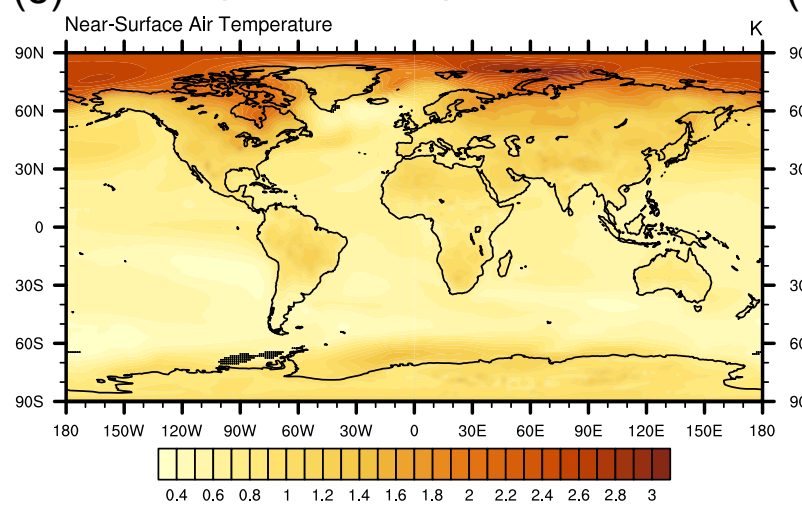

(b)

G1-piControl

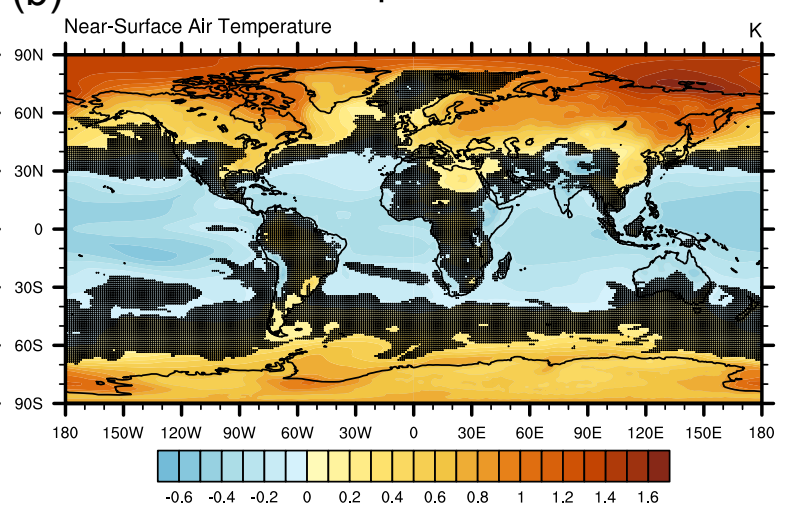

(d)

G2-piControl

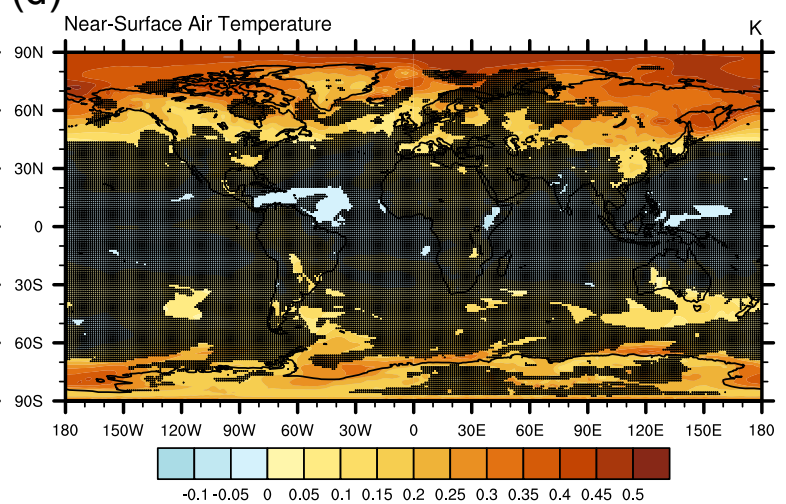

(f)

G3_2030_2069-rcp45_2010_2029

Near-Surface Air Temperature

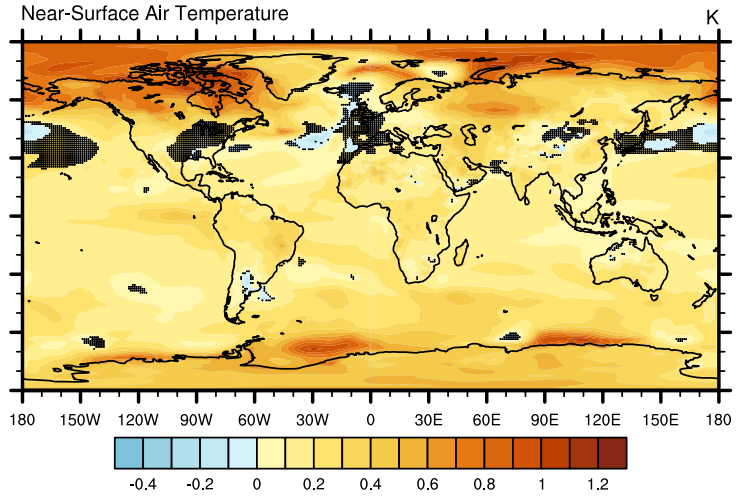

(g)

G4_2030_2069-rcp45_2010_2029

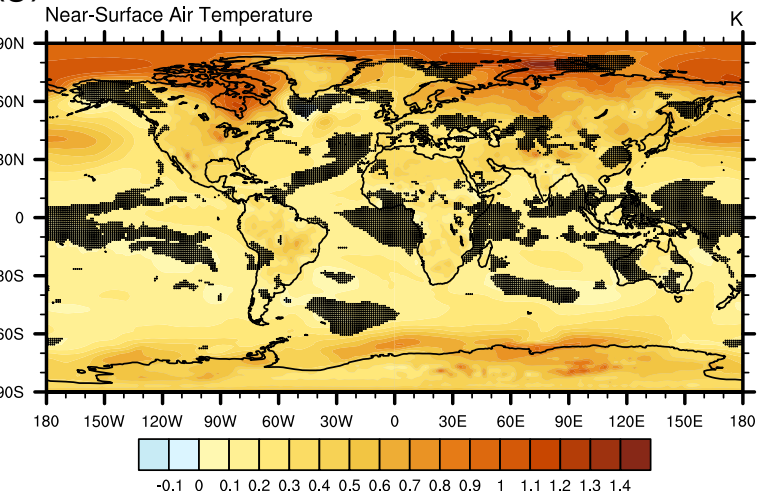


(a)

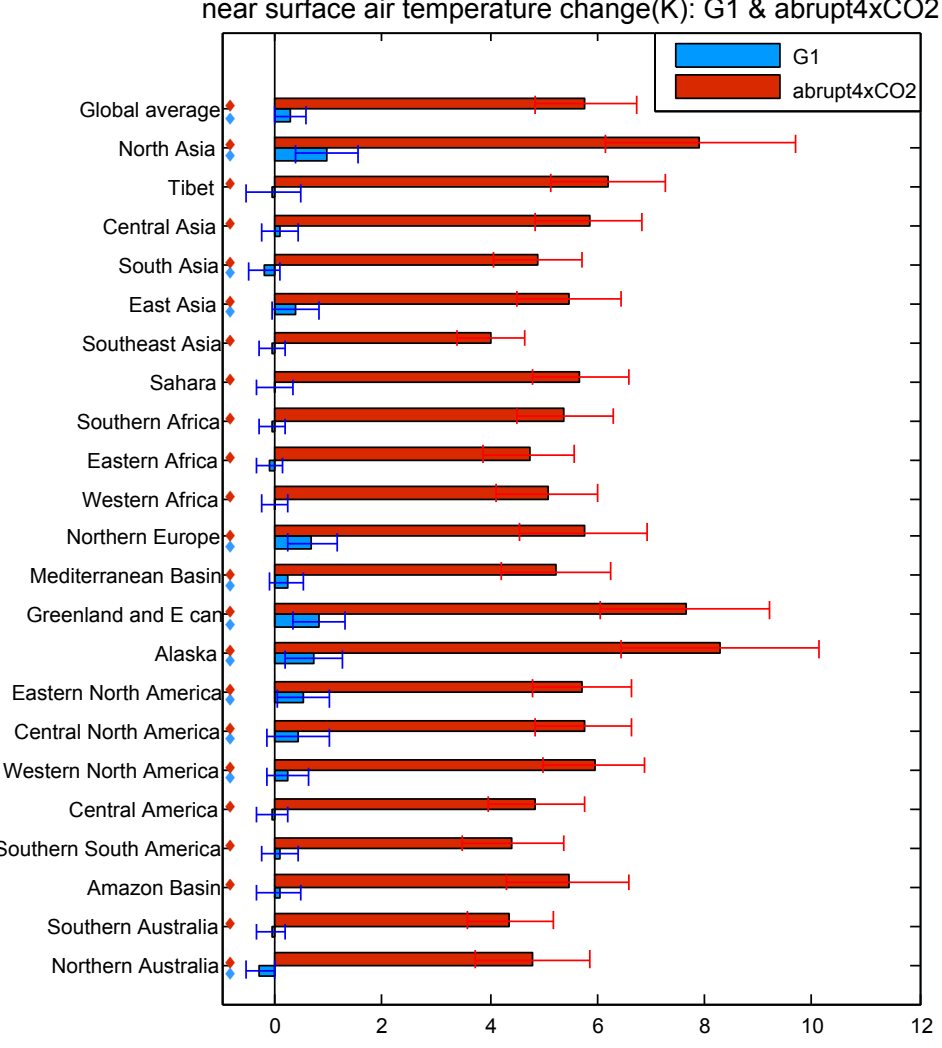

(b)

near surface air temperature change $(\mathrm{K})$ : G2 \& 1pctCO2

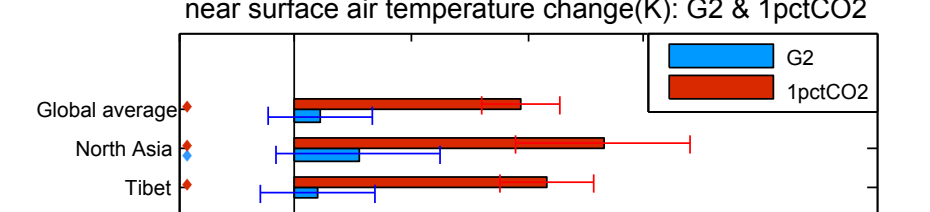

Central Asia
South Asia
East Asia

Southeast Asia *

Sahara

Southern Africa

Eastern Africa

Western Africa

Northern Europe-

Mediterranean Basin

Greenland and E can?

Alaska

Eastern North America

Central North America

Western North America

Central America

Southern South America

Amazon Basin

Southern Australia

Northern Australia

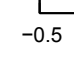

(c)

regional near surface air temperature change(K): G3 \& G4 \& rcp45

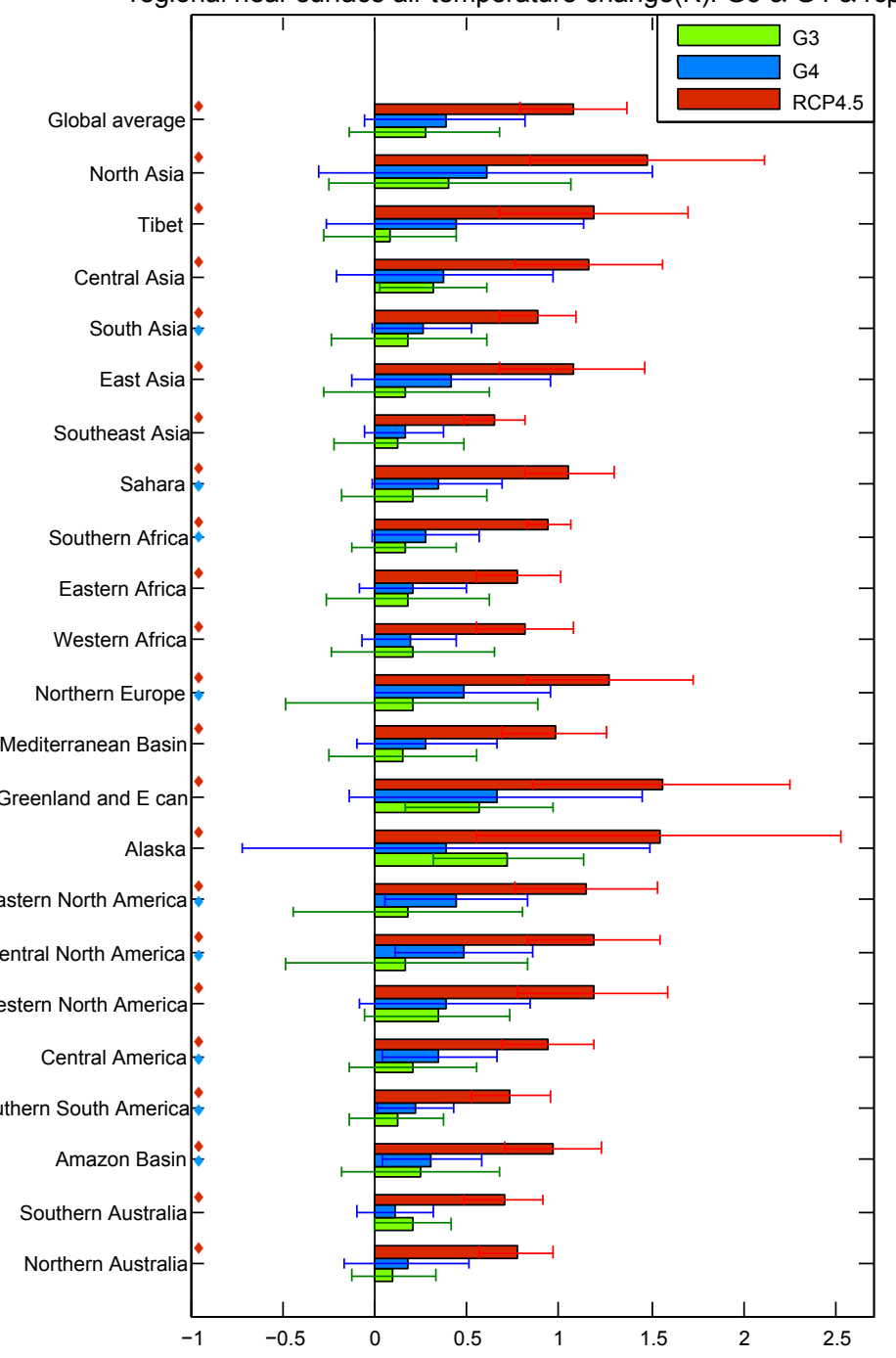


(a)

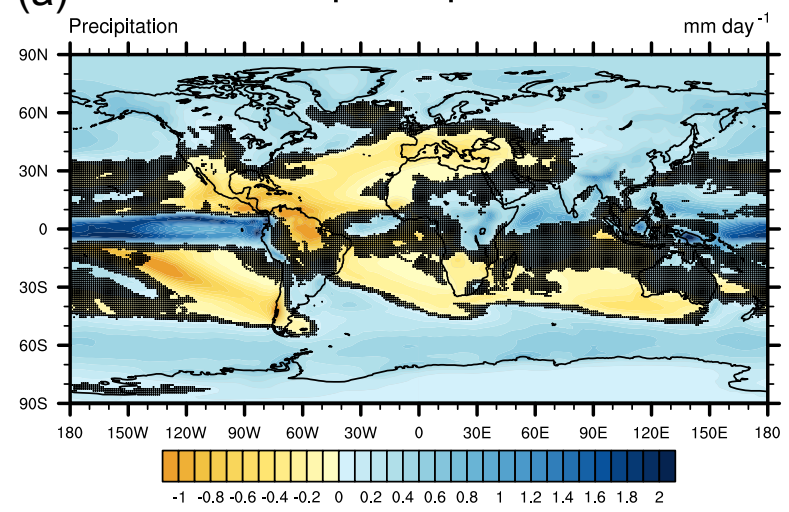

(c)

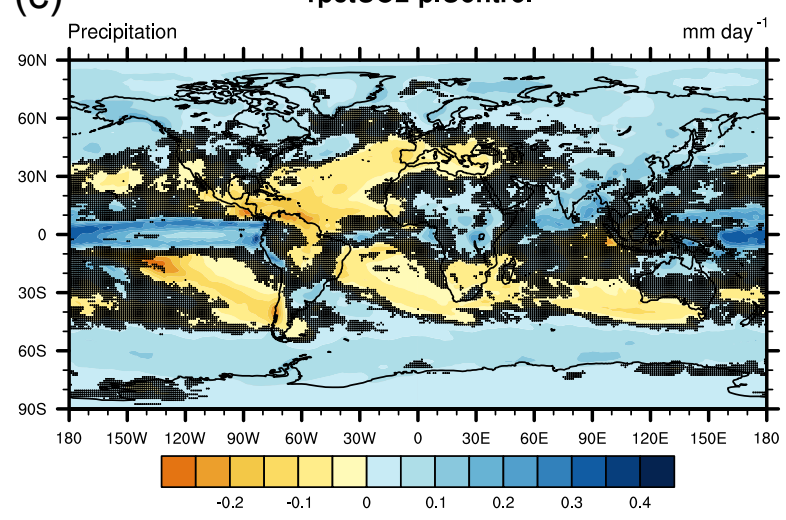

(e)

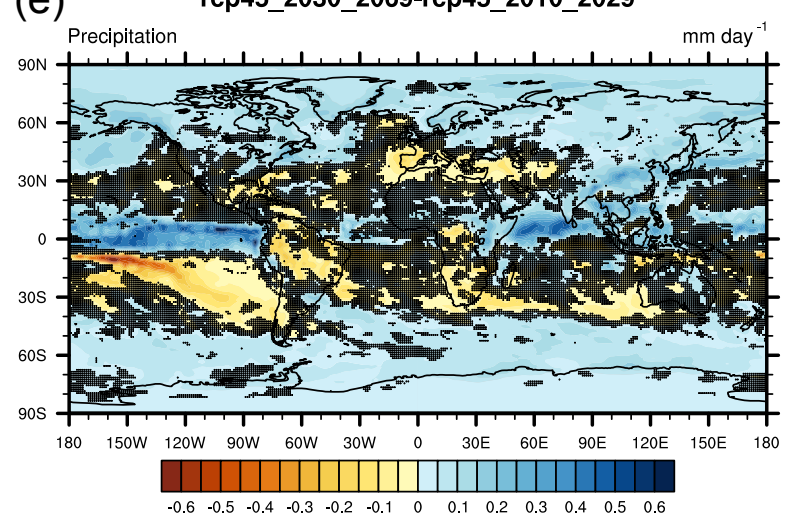

(b)

G1-piControl

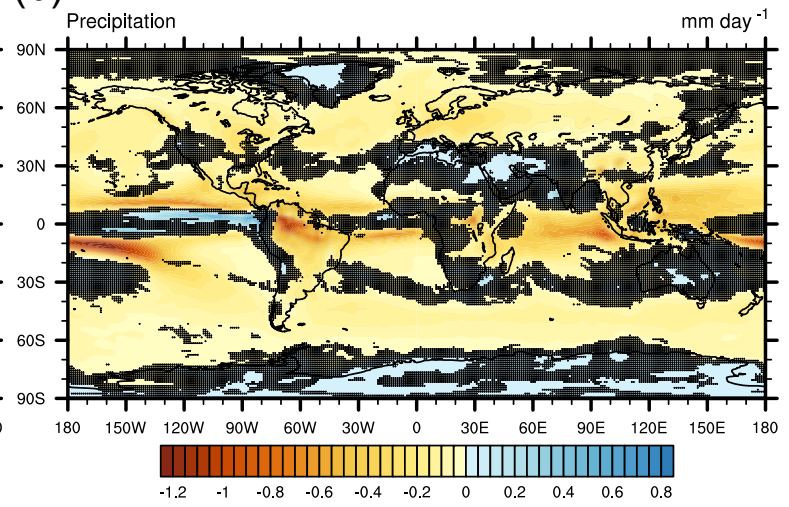

(d)

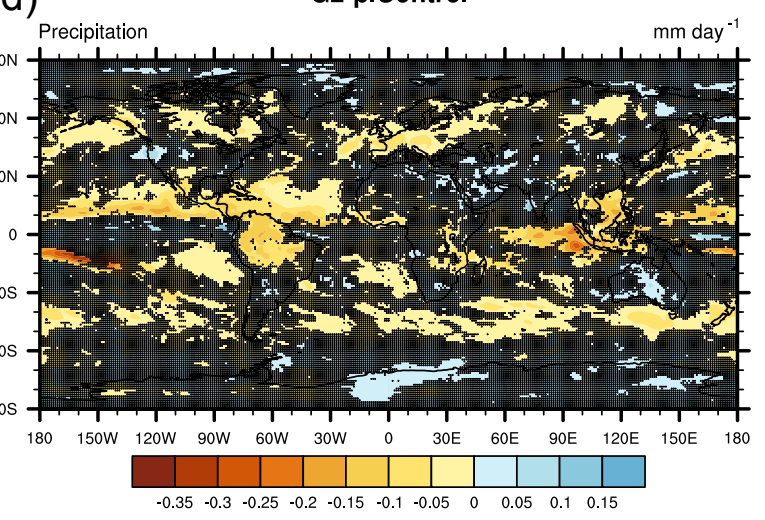

(f)

G3_2030_2069-rcp45_2010_2029

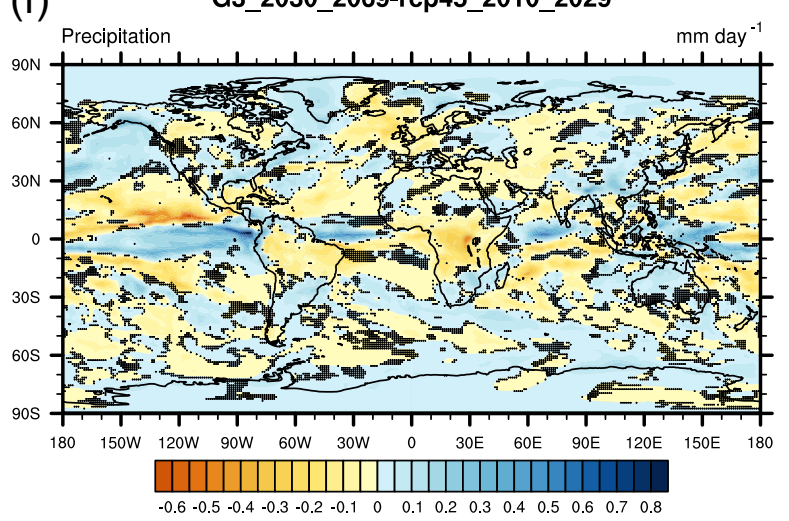

(g)

G4_2030_2069-rcp45_2010_2029

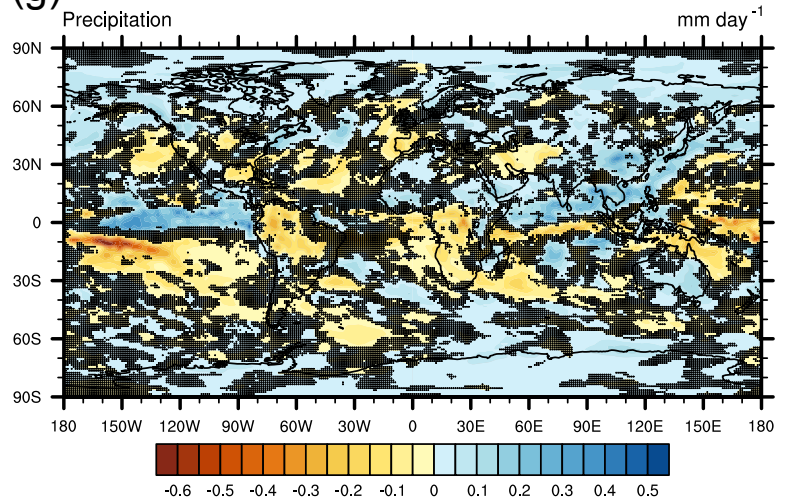


(a)

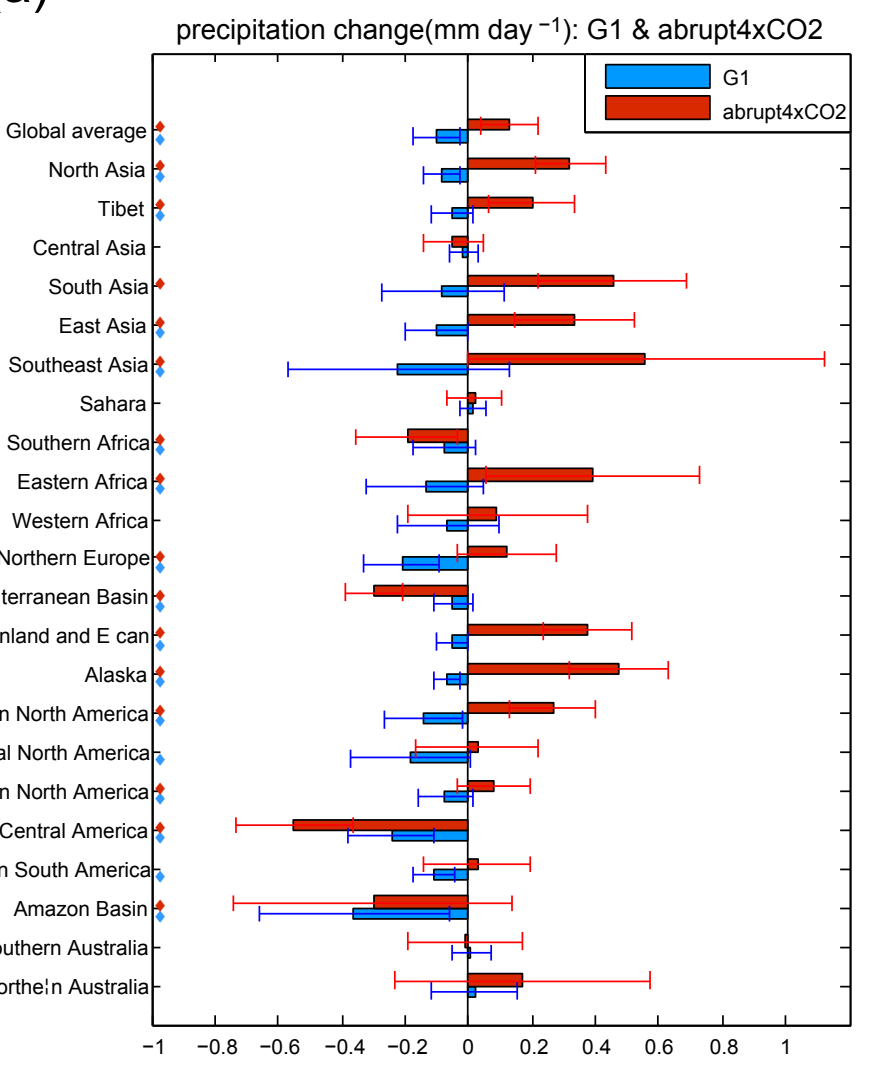

(b)

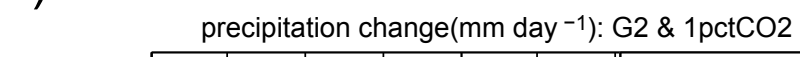

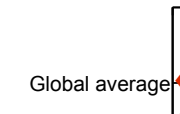

North Asia Tibet

Central AsiaSouth Asia East Asia Southeast AsiaSahara-

Southern Africa Eastern Africa Western Africa-

Northern EuropeMediterranean BasinGreenland and E can * Alaska Eastern North America Central North AmericaWestern North America Central America Southern South AmericaAmazon BasinSouthern AustraliaNorthelin Australia

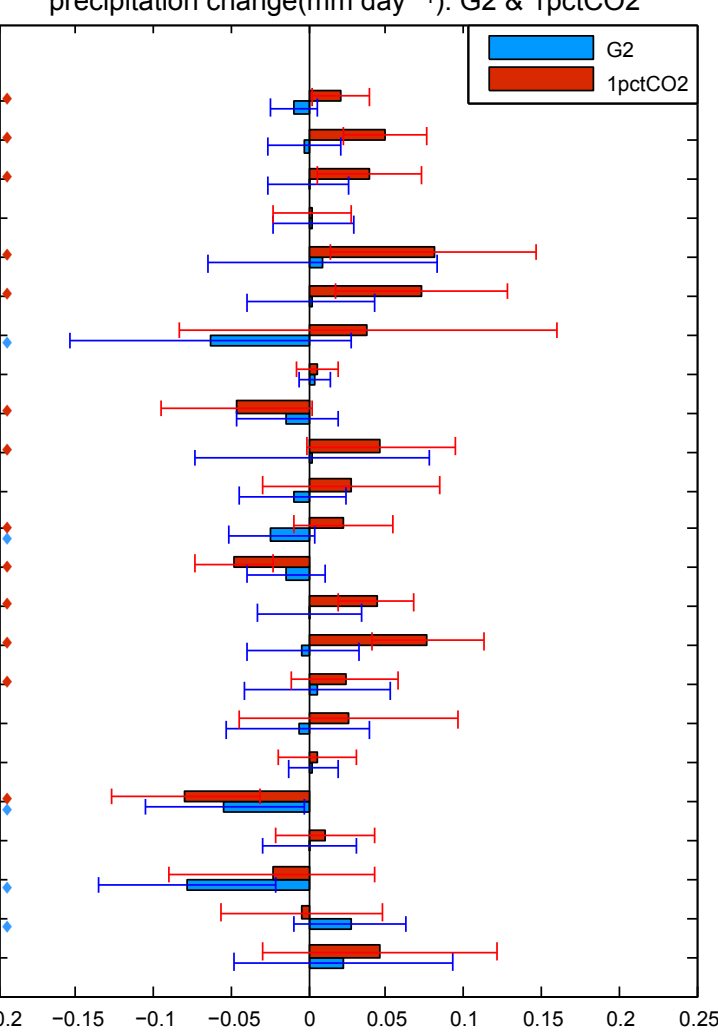

(c)

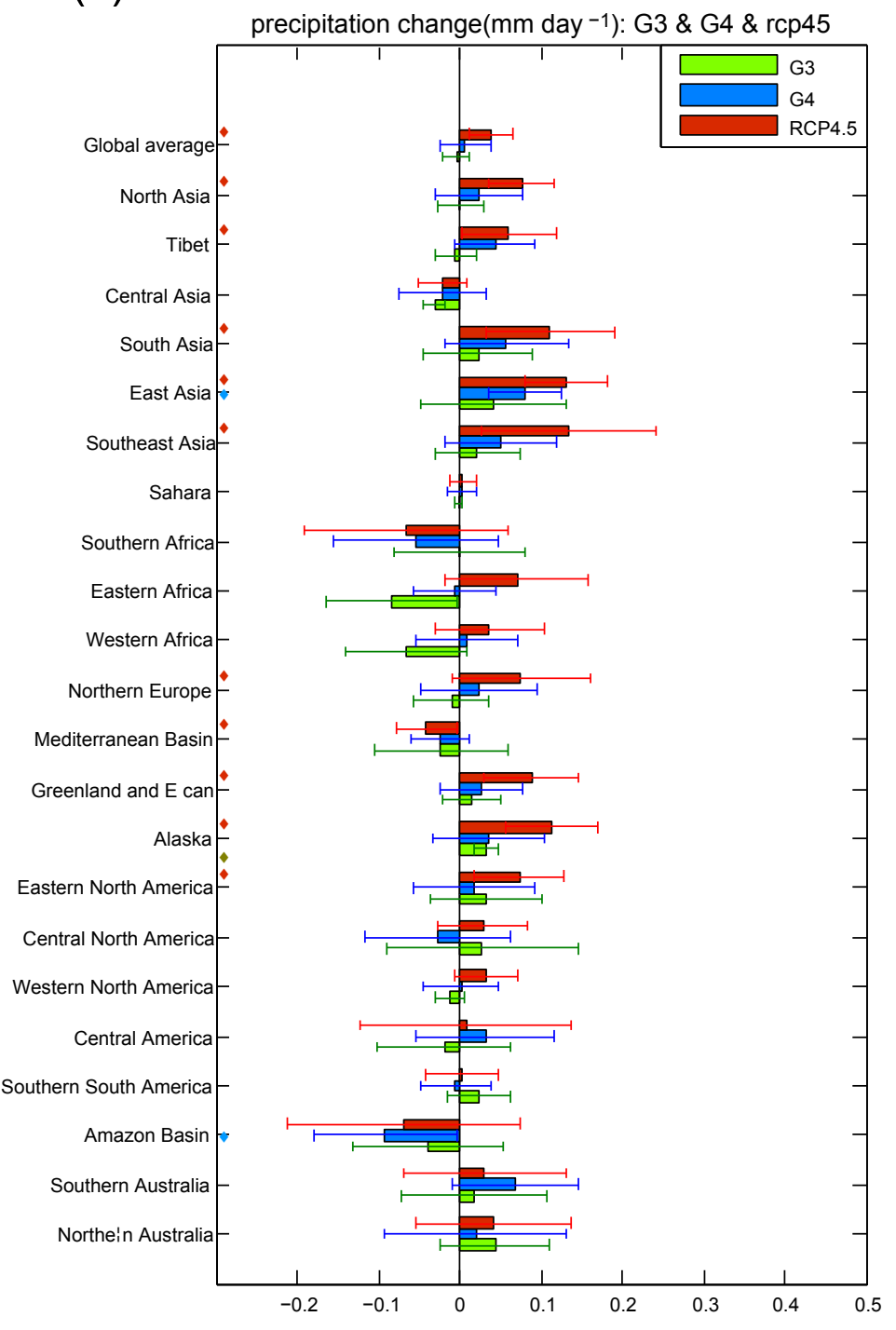


temperature regional inequality
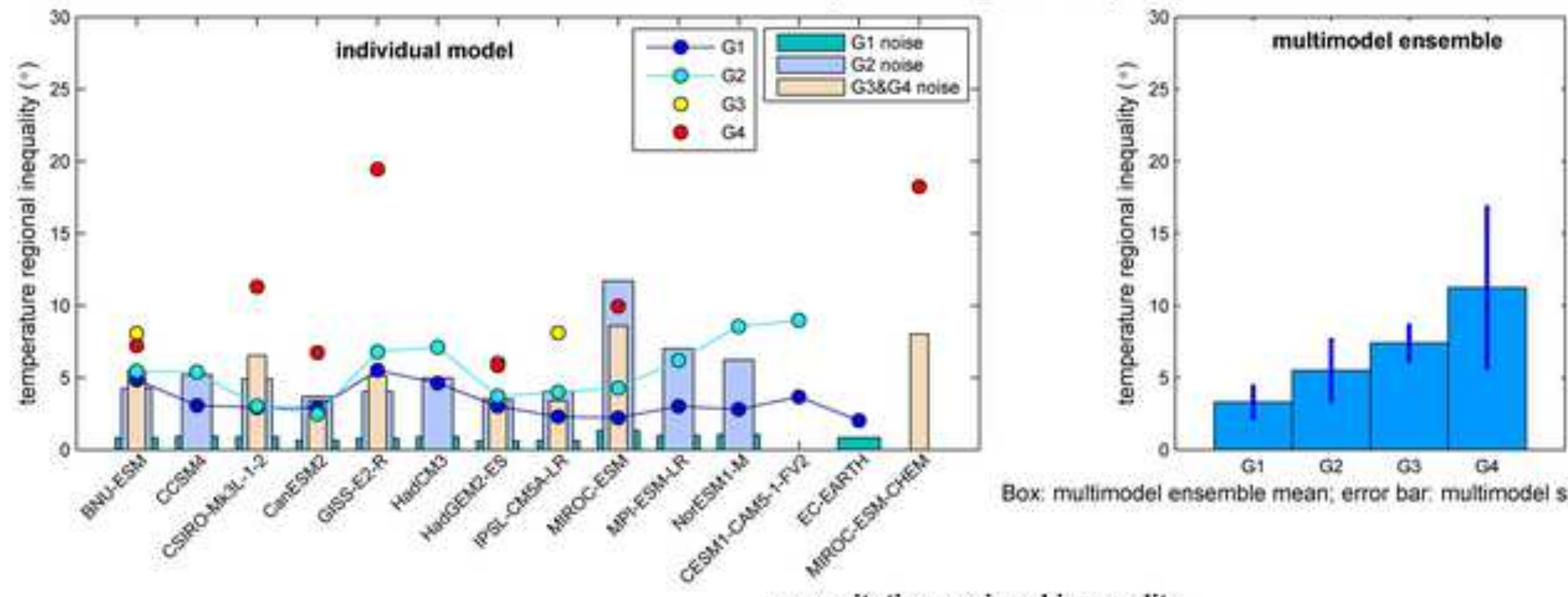

Box multimodel ensemble mean; error bar: multimodel standard deviation

precpitation regional inequality
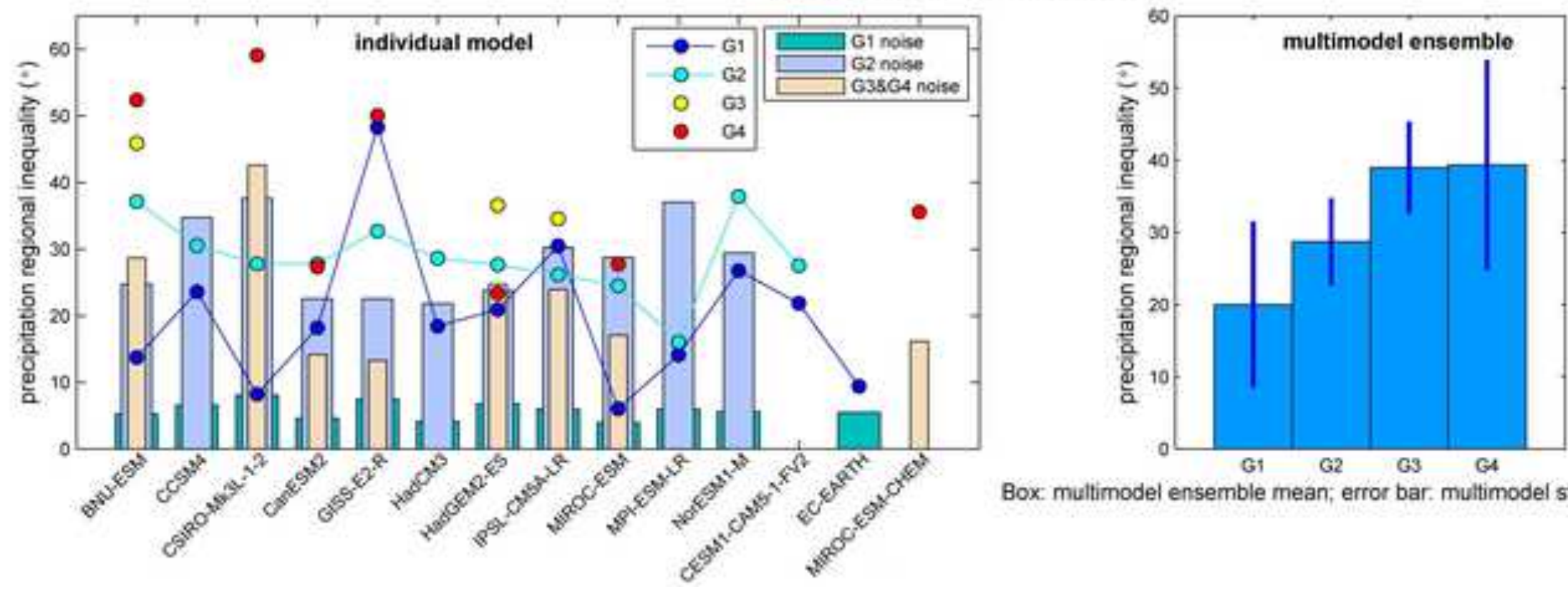

Box: multimodel ensemble mean; error bar. multimodel standard deviation 


\section{temperature actual effectiveness}
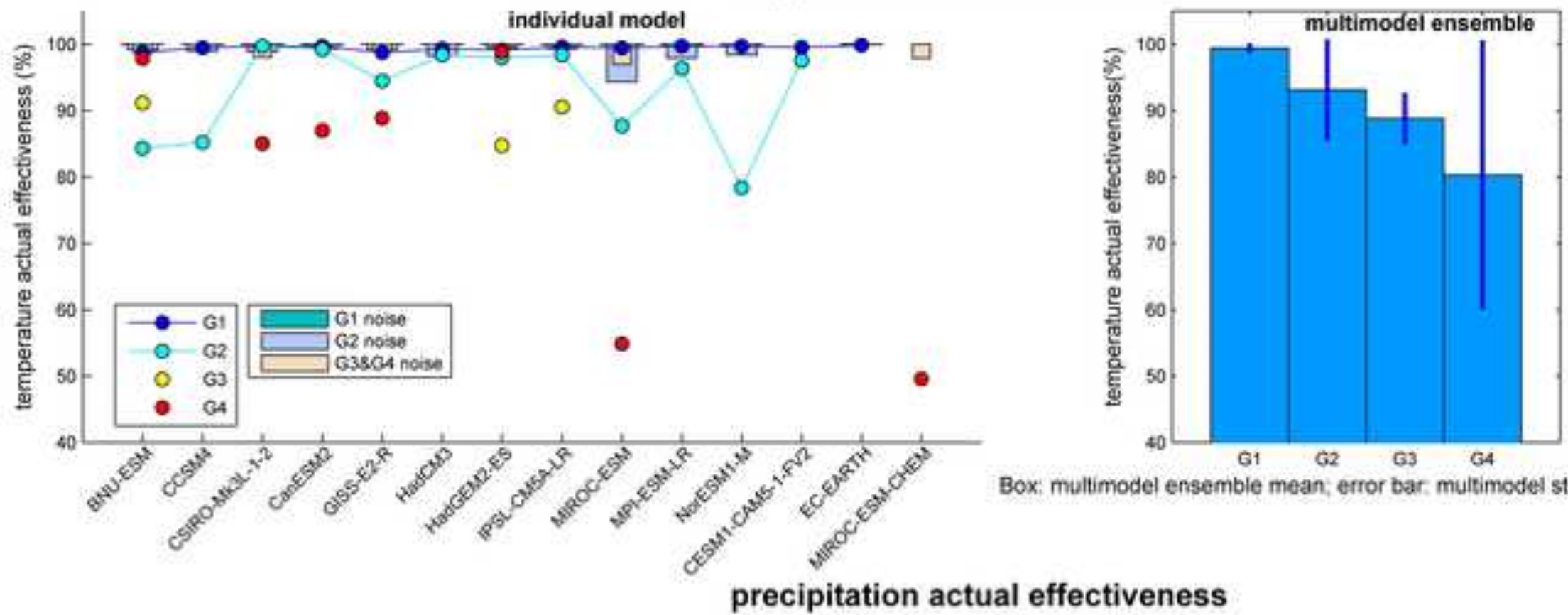

Box: multimodel ensemble mean; error bar multimodel standard deviation
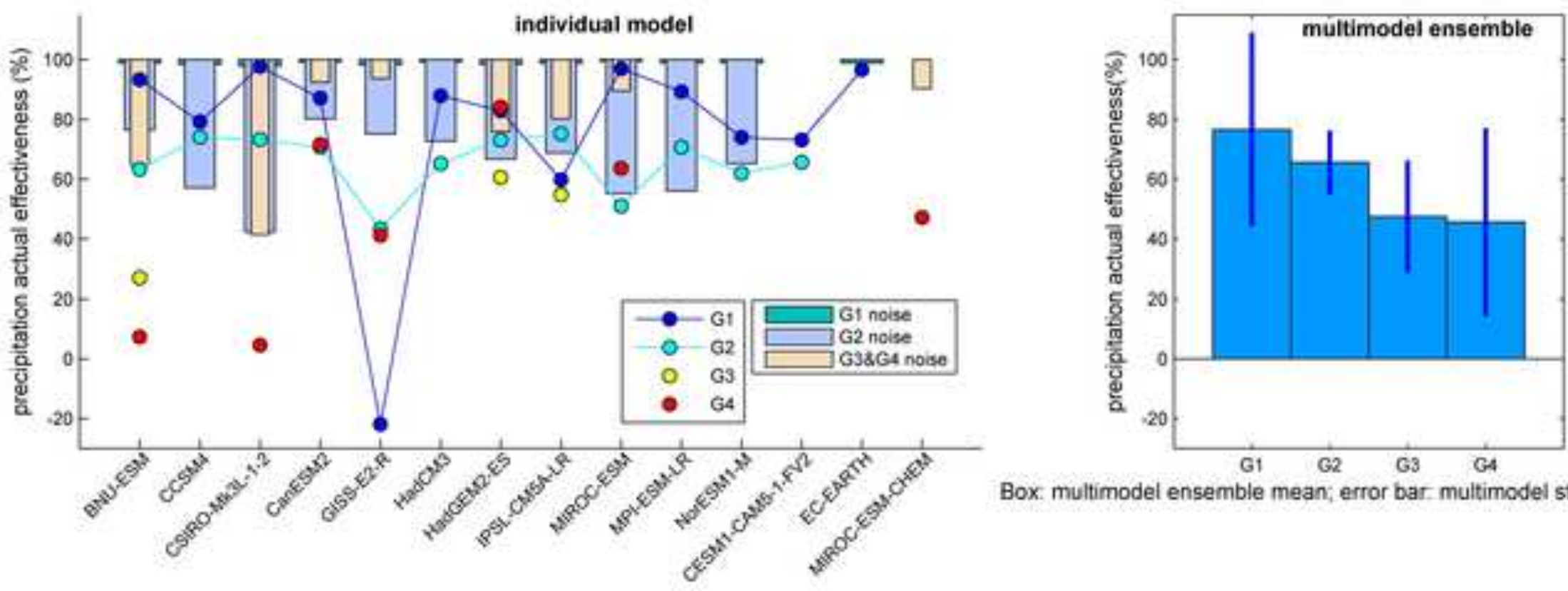

Box: multimodel ensemble mean; error bar multimodel standard deviation 